\title{
Pyrrolidinium Containing Ionic Liquid Electrolytes for Li-Based Batteries
}

\author{
Louise M. McGrath and James F. Rohan * $\mathbb{D}$
}

Electrochemical Materials and Energy Group, Tyndall National Institute, University College Cork, Lee Maltings, T12 R5CP Cork, Ireland; louise.mcgrath@tyndall.ie

* Correspondence: james.rohan@tyndall.ie; Tel.: +353-21-234-6224

Academic Editor: Paul Nancarrow

Received: 30 November 2020; Accepted: 16 December 2020; Published: 18 December 2020

check for updates

\begin{abstract}
Ionic liquids are potential alternative electrolytes to the more conventional solid-state options under investigation for future energy storage solutions. This review addresses the utilization of IL electrolytes in energy storage devices, particularly pyrrolidinium-based ILs. These ILs offer favorable properties, such as high ionic conductivity and the potential for high power drain, low volatility and wide electrochemical stability windows (ESW). The cation/anion combination utilized significantly influences their physical and electrochemical properties, therefore a thorough discussion of different combinations is outlined. Compatibility with a wide array of cathode and anode materials such as LFP, $\mathrm{V}_{2} \mathrm{O}_{5}$, Ge and $\mathrm{Sn}$ is exhibited, whereby thin-films and nanostructured materials are investigated for micro energy applications. Polymer gel electrolytes suitable for layer-by-layer fabrication are discussed for the various pyrrolidinium cations, and their compatibility with electrode materials assessed. Recent advancements regarding the modification of typical cations such a 1-butyl-1-methylpyrrolidinium, to produce ether-functionalized or symmetrical cations is discussed.
\end{abstract}

Keywords: anode; cathode; electrolyte; energy storage; ionic liquids; lithium ion batteries; lithium metal batteries; polymer gel electrolyte; pyrrolidinium

\section{Introduction}

Due to advancements in the fields of electronics, and the deployment of wireless communication systems, mobile devices and ubiquitous services, the Internet of Things (IoT) has been able to step out of its infancy, and is constantly gaining traction, with current trends suggesting that 75.44 billion IoT devices should be connected by 2025 [1]. This progress has been realized due to the integration of several enabling technologies (energy harvesters, sensors and energy storage), which can create autonomous devices, which can then be deployed and forgotten.

However, one of the main constraints to the deployment of IoT devices is the power requirement. Energy harvesters alone are rarely sufficient to power the IoT devices, due to their limitations, e.g., availability of light for photovoltaic cells. Therefore, the coupling of energy storage devices with appropriate power management systems is required. Advancements in sensor technologies are leading to rapid miniaturization, which is hindered by the large energy storage devices. This highlights the need for rapid development of miniaturized energy storage devices with a high power capability for sense, actuation and communication [2].

A crucial hurdle towards the development of feasible microbatteries is that the charge capacity decreases with size. The decrease in energy originates from the fact that the capacity of a battery scales linearly with the volume of the electrodes. Therefore, the volumetric capacity of the electrode material is more important than the gravimetric capacity [3-5]. The most commonly investigated microbattery technology relies on lithium cobalt oxide (LCO) materials coupled with Li metal and a 
solid-state electrolyte. The scarcity of cobalt (Co) [6] and its price instability [7] make it unattractive for continuous use, and researchers are investigating electrode materials with reduced Co content or are entirely Co-free. High operational temperatures are required for most microbatteries without LCO cathodes due to the low ionic conductivity of the compatible electrolyte material and sluggish $\mathrm{Li}^{+}$ diffusion [8-18].

There is a need to identify potential alternative electrolytes with high power capability beyond what is possible with present day inorganic solid-state materials. The objective of this review is to provide a comprehensive analysis of ionic liquid electrolytes, particularly pyrrolidinium-based ILs. Firstly, a brief discussion of various IL cations, which can be utilized for energy storage applications is presented. An in-depth analysis of pyrrolidinium-based ILs is given due to their superior versatility when compared to other ILs such as imidazolium. The ethyl-, propyl- and butyl- analogues of pyrrolidinium ILs have shown applicability for energy storage applications each with different physico- and electrochemical properties. Their compatibility with a variety of anion materials is discussed. The formation of polymer gel analogues is outlined where applicable, and the liquid and polymer gel half- and full-cell compatibility with a wide variety of electrode materials is shown. Functionalized pyrrolidinium-based electrolytes are also presented and contrasted with their non-functionalized counterparts.

\section{Ionic Liquids (IL) for Energy Storage Applications}

Examples of ILs that have been identified as suitable electrolytes include: ammonium [19-46], pyridinium [47-50], piperidinium [51-77], imidazolium [78-97] and pyrrolidinium. Each cation offers favorable properties, for example, piperidinium ionic liquids possesses non-flammability, large electrochemical window ( -3.8 to $2.5 \mathrm{~V}$ vs. $\mathrm{Pt}$ ) [98], and inherent conductivity, which make them suitable for use as an electrolyte solvent in electrical energy storage devices [51,52].

Numerous studies have been carried out to determine the most suitable cation-type for use with Li-based batteries. Ammonium cations, particularly the liquid analogue, are suitable for Li and Li-ion batteries as they show good cyclability with various cathode and anode materials in both thin-film and nanostructured configurations. In some instances, full cell capabilities have been demonstrated incorporating high capacity anode materials such as $\mathrm{Si}$, thus showing their suitability as liquid electrolytes [29]. Unfortunately, there is little literature available for the polymer gel analogues, with the exception of TMHA-TFSI [31] and DEME-TFSI ILs [40-43], which limits its use with solid-state batteries. In addition, high operation temperatures $\left(>60{ }^{\circ} \mathrm{C}\right)$ are required in order for appreciable capacities to be obtained using the polymer gel analogue.

Pyridinium-based [47-50] ILs have been utilized as a solid state electrolyte (polymer gel form) where Gupta et al. [47] and Yang et al. [49] synthesized promising polymer gel electrolytes, which offer good cyclability with lithium iron phosphate (LFP) electrodes and high coulombic efficiencies. To the best of our knowledge, no other research has been carried out with other cathode or anode materials, which may suggest that the compatibility with other electrode materials may be limited, therefore hindering its use as an electrolyte for Li-ion batteries.

The focus of piperidinium-based ILs is mainly concerned with $\mathrm{N}$-propyl- $\mathrm{N}$-methylpiperidinium $\left(\mathrm{PP}_{13}\right)$-based electrolytes, due to its compatibility with various electrode materials at different temperatures [51-77]. However, further research is required to advance the utilization of PP 13 TFSI in both its liquid and polymer gel analogue forms, in addition to a multitude of other piperidinium-based ILs [99-107]. Other piperidinium cations are not as extensively studied, however, they were investigated with a range of cathode and anode materials across a wide variety of temperatures (room temperature to $\left.150{ }^{\circ} \mathrm{C}\right)$.

Extensive research has been carried out on 1-ethyl-3-methylimidazolium-based ILs. This IL has shown compatibility with a wide range of cathode and anode materials in both its liquid [78-87] and polymer gel form [88-97]. Other imidazolium-based ILs have been synthesized and characterized, and their physicochemical properties were determined [108-110]. More recently, 
functionalized-imidazolium-based ILs are being investigated including phosphonate- [111], and Si-functionalized ILs [112,113].

\section{Overview of Ionic Liquids}

Ionic liquids offer a unique set of properties that make them important candidates for a number of energy related applications. ILs are salts, whose ions are poorly coordinated, thus resulting in their solvent-like appearance at temperatures below $100^{\circ} \mathrm{C}$ [114]. They have garnered interest as alternatives to both organic and solid-state electrolytes because of their tunable properties, which depends upon the cation and anion combination. They can be tuned to exhibit low volatility coupled with high ionic conductivity and electrochemical and thermal stability. It is therefore possible to design electrolytes, for specific applications such as, 1-butyl-1-methylpyrrolidinium bis(trifluoromethylsulfonyl)imide, which exhibits high lithium ionic conductivity $\left(3 \mathrm{mS} \mathrm{cm}^{-1}\right)$ at room temperature for energy storage [115].

Diffusion within ILs is unique as fluid mechanic equations under simplified conditions are not applicable [116-124], for example, diffusion in ILs is similar to that in solid-state materials [116-118] but further complicated by the ever-changing diffusion pathways caused by the ion pairings [119-124]. ILs are often viscous fluids and a direct channel for diffusion is not provided, in conjunction with blocking interactions between the electroactive species and IL ions. For these reasons, conventional one-dimensional diffusion as observed in organic electrolytes cannot be assumed. Diffusing ions can collide with IL ions and either be deviated from the straight pathway or deflected. Therefore, it has been suggested that the viscosity of the ILs is not the primary factor for slow diffusion but the active interaction of $\mathrm{Li}^{+}$ions in the structure of the ILs [125].

As with organic solvents the electrochemical reduction of the IL cation can result in the formation of a solid-electrolyte interphase (SEI) layer, however, the anion can also contribute to its formation. The anion plays a substantial role in the electrochemical stability of the IL, which in turn affects that electrochemical stability window (ESW). Sun et al. [126] found that the ESW of 1-ethyl-3-methylimidazolium ([emim $]^{+}$) based ILs with different aprotic heterocyclic anions is highly dependent on the anion. Hayyan et al. [127] investigated different cation/anion combinations to determine the effect of the IL structure on its ESW. They determined that certain cations such as phosphonium $\left(\mathrm{P}_{14,666}{ }^{+}\right)$have better reductive stability than pyrrolidinium and imidazolium. Similarly, certain anions (TFSI ${ }^{-}$) offer significantly better oxidative stability than others (e.g., $\mathrm{OTf}^{-}$). Understanding the reductive and oxidative limits of cations and anions permits the correct combination to be chosen, in addition to tailoring the combination to suit specific potential needs.

Another parameter to consider is the availability of a "free" proton on the cation of certain ILs. ILs whose cations have this "free" proton are called protic ILs, while those without are referred to as aprotic ILs (AIL) [128]. Both offer the favorable characteristics associated with ILs such as negligible vapor pressure, non-flammability and high chemical and thermal stabilities [129-131] and some also exhibit high ionic conductivity [129-131] but AILs are utilized more frequently as electrolytes for lithium-based batteries due to their favorable properties such as wider ESW when compared to their protic counterparts [132].

This review will focus on one particular family of AIL cations, the pyrrolidinium cations, due to their versatility and compatibility with Li-based battery materials. They enable the use of different cations including ethyl-, propyl- and butyl-, in addition to ether functionalization. The structure and name of the cations that will be discussed in this review are outlined in Table 1. 
Table 1. Structures of pyrrolidinium cations and commonly used anions discussed in this review.

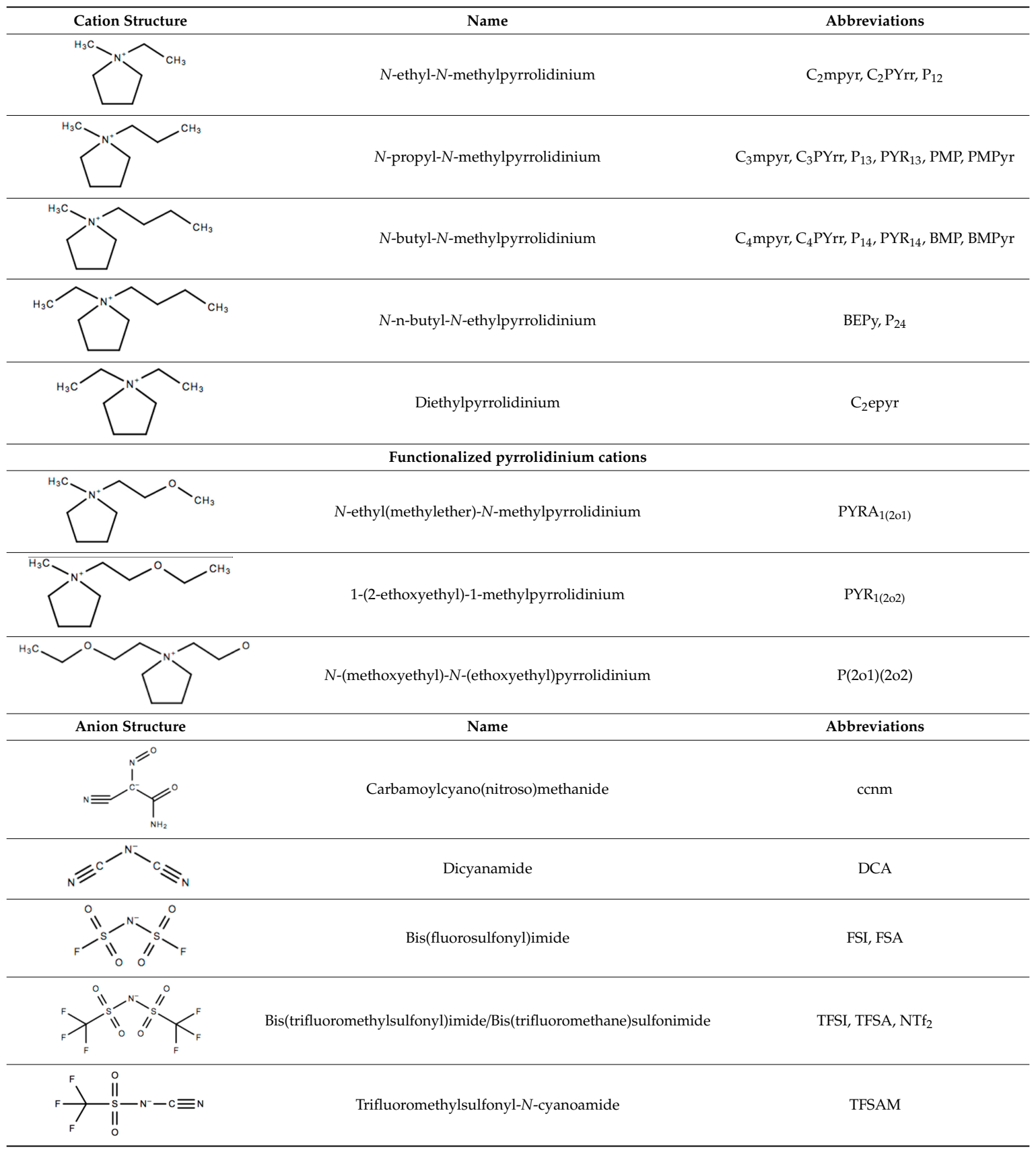

\section{4. $N$-ethyl- $N$-methylpyrrolidinium $\left(\mathrm{C}_{2} \mathrm{mpyr}\right)$-Based ILs}

$\mathrm{N}$-ethyl- $\mathrm{N}$-methylpyrrolidinium $\left(\mathrm{C}_{2} \mathrm{mpyr}\right)$-based ILs are solids at room temperature [133], much like other ILs consisting of ethyl-based cations $[53,134] . \mathrm{C}_{2}$ mpyr-based ILs have hindered rotation about the axis, which leads to increased viscosity $\left(9.3 \mathrm{cP}\right.$ vs. $8.3 \mathrm{cP}$ and $8.6 \mathrm{cP}$ at $\left.90{ }^{\circ} \mathrm{C}\right)$ when compared to propyl or butyl side chains, respectively [133]. Many of the electrolytes containing $\mathrm{C}_{2}$ mpyr-cations are polymer gel based rather than liquid, where to date, the most commonly used anion for $\mathrm{C}_{2}$ mpyr-based electrolytes is bis(fluorosulfonyl)imide $\left(\mathrm{FSI}^{-}\right)$, with either LiTFSI or LiFSI salt.

\subsection{PVDF-HFP/PEO Containing Polymer Electrolytes}

Conventional polymer matrices such as PVDF have been investigated with $\mathrm{C}_{2}$ mpyrFSI and LiFSI salt $[135,136]$. The optimum LiFSI concentration was determined to be $10 \mathrm{wt} \%$ as it offered a high 
ionic conductivity $\left(10^{-6} \mathrm{~S} \mathrm{~cm}^{-1}\right.$ vs. $\left.10^{-7} \mathrm{~S} \mathrm{~cm}^{-1}\right)$, when compared to $1 \mathrm{wt} \%$ LiFSI. The effect of PVDF concentration was also investigated as it interacts on a molecular level with $\mathrm{C}_{2}$ mpyrFSI, which leads to increased molecular disorder [135]. The optimum PVDF content was determined to be $10 \mathrm{wt} \%$ as it provided the best thermal and ionic conductivity properties. Compatibility with Li metal was shown using a combination of cycling and EIS analysis. At higher LiFSI concentrations (>10 wt \%), a continuous increase in the interfacial resistance was observed, which is indicative of continuous SEI layer formation. For all investigated salt concentrations, cracks eventually formed on the surface of $\mathrm{Li}$ metal, which allowed for the formation of dendrites, however, this occurred after hundreds of cycles. Further optimization of the Li/electrolyte interface may mitigate the dendrite formation, which could allow for the creation of a $\mathrm{C}_{2}$ mpyrFSI-based microbattery as the polymer gel exhibited compatibility with $\mathrm{LiNi}_{0.3} \mathrm{Mn}_{0.3} \mathrm{Co}_{0.3} \mathrm{O}_{2}$ (NMC) [136]. A high cut-off voltage of $4.6 \mathrm{~V}$ was utilized where an initial discharge capacity of $120 \mathrm{mAh} \mathrm{g}^{-1}$ was obtained, which decreased over 30 cycles due to chemical and structural changes [137], despite this, coulombic efficiencies were maintained above $90 \%$ over the course of cycling. Its performance with $\mathrm{NCM}$ is comparable to a conventional electrolyte $\left(1 \mathrm{M} \mathrm{LiPF}_{6}\right.$ in EC/DEC (1:1)) [136].

\subsection{Other Polymer Matrices}

Other authors have shown the viability of $\mathrm{C}_{2}$ mpyr-based IL electrolytes when utilizing a polymeric ionic liquid (PIL) rather than conventional polymer matrices, due to their higher ionic conductivities in addition to better film forming properties and desirable electrochemical properties [138,139]. Li et al. [140] utilized the PIL: poly(diallyldimethylammonium) bis(trifluoromethylsulfonyl)imide (P(DADMA)-TFSI) with $\mathrm{C}_{2}$ mpyrFSI and LiTFSI salt. An ionic conductivity of $1.54 \times 10^{-4} \mathrm{~S} \mathrm{~cm}^{-1}$ at $25{ }^{\circ} \mathrm{C}$ was obtained for a 50:20:50 P(DADMA)-TFSI:LiTFSI: $\mathrm{C}_{2}$ mpyrFSI ratio. This value is significantly improved when compared to the electrospun PVDF-based polymer gel electrolytes by Zhou et al. $[135,136]$. Compatibility with Li metal was exhibited with 1000 cycles achieved in a symmetrical cell without short circuiting. In addition, good electrochemical performances were noted with LFP across a variety of temperatures $\left(25^{\circ} \mathrm{C}, 40^{\circ} \mathrm{C}\right.$ and $\left.80^{\circ} \mathrm{C}\right)$ with initial discharge capacities and coulombic efficiencies of $122.3 \mathrm{mAh} \mathrm{g}^{-1}$ with $77.8 \%, 150.2 \mathrm{mAh} \mathrm{g}^{-1}$ with $89.2 \%$ and $163.6 \mathrm{mAh} \mathrm{g}^{-1}$ with $97.6 \%$, respectively, being obtained at $0.2 \mathrm{C}$. All cells maintained their capacity over the course of 150 cycles, with an improvement in the capacity for the cell cycled at $25^{\circ} \mathrm{C}$. Unlike Zhou et al. [135,136], dendrite formation was hindered within the P-DADMA-TFSI-based electrolyte, however, post-mortem analysis revealed the presence of pits on the surface of the Li metal electrode, which may yield dendrites upon prolonged cycling as shown in Figure $1[135,140]$.
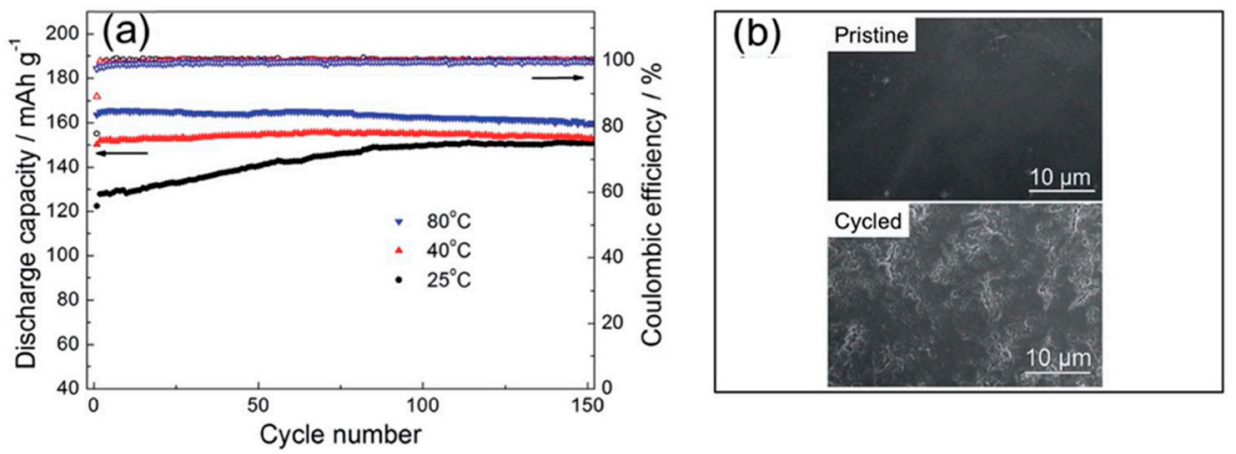

Figure 1. The performance of Li|SPE: 50:20:50 P(DADMA)-TFSI:LiTFSI: $\mathrm{C}_{2}$ mpyrFSI|LiFePO $_{4}$ cells: (a) discharge capacity and coulombic efficiency versus cycle number at $25^{\circ} \mathrm{C}, 40{ }^{\circ} \mathrm{C}$ and $80{ }^{\circ} \mathrm{C}$ at a current rate of $0.2 \mathrm{C}$, (b) SEM images of the pristine lithium and lithium anodes after a rate test $(0.2 \mathrm{C}$, 0.5 C, 1 C and 0.2 C). Adapted from Li et al. [140] with permission from The Royal Society of Chemistry. 


\subsection{Encapsulation of Electrode Particles}

The utilization of $\mathrm{C}_{2}$ mpyr-based ILs is not limited solely to polymer gel electrolytes that are sandwiched between two electrodes as other research groups have investigated the in-situ formation of the ionogel electrolyte within an electrode to ensure encapsulation of the electrode particles [32]. SEM and EDX analysis of the electrodes was used to show the penetration of the ionogel into the electrode as the electrode particles were encapsulated by the ionogel (Figure 2). This is a viable method for ensuring high surface contact between the gel-based electrolyte and the electrode, particularly where particle or nanostructured materials were utilized. A full cell was assembled by Ogawa et al. [32] to show the enhanced capabilities of the encapsulated cathode and anode particles. The full cell consisted of an LTO anode and NMC cathode. The internal resistance of the battery plays a significant role in full cell performances. Ogawa et al. [32] showed a significant increase $(\sim 0.34 \mathrm{mAh})$ in the batteries discharge capacity when the $\mathrm{C}$-rate was decreased from 0.05 to $0.01 \mathrm{C}$. These results pave the way for further analysis of polymeric ionic liquid-based electrolytes as they can be synthesized using solvent free processes and have high wettability of the electrode material.
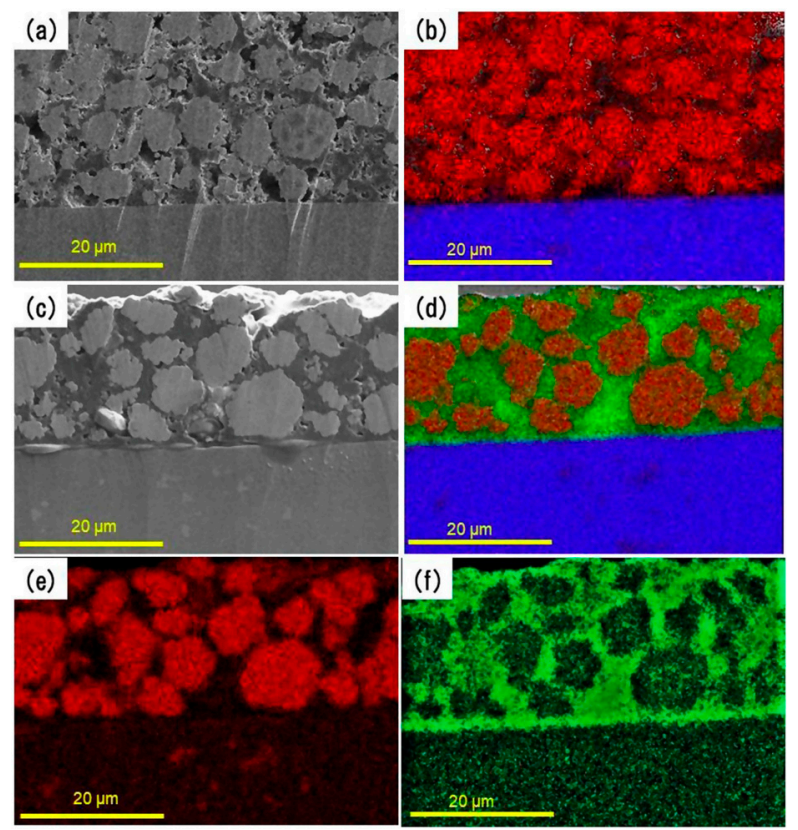

Figure 2. SEM and EDX-mapping images of the sectional view of the NMC cathode. $(\mathbf{a}, \mathbf{b})$ are with no ionogels (control sample) and (c,d) are with ionogel respectively. Red, green and blue colors indicate cobalt (NMC), sulphur (ionogels) and aluminum (current collector), respectively. (e,f) are EDX-mapping images of cobalt and sulphur extracted from (d). Reprinted with permission from Ogawa et al. [32].

\subsection{Alternative Cation/Anion Combinations}

In addition to the utilization of PILs, further research is being carried out to determine alternative cation-anion combinations of the $\mathrm{C}_{2}$ mpyr-based electrolytes, which may yield more favorable properties than typical FSI- and TFSI-based ILs. Recently, Yamaguchi et al. [141] investigated the effect of various anions on the properties of the IL salt, as it has been reported that FSI-based salts offer higher ionic conductivities $\left(1.23 \times 10^{-6} \mathrm{~S} \mathrm{~cm}^{-1}\right)$ than TFSI-based salts [142]. In addition, high ionic conductivities of $1 \times 10^{-3} \mathrm{~S} \mathrm{~cm}^{-1}$ have been reported for carbamoylcyano(nitroso)methanide (ccnm) anions in combination with $\mathrm{C}_{2}$ mpyr cations [143]. Yamaguchi et al. [141] determined that the ionic radius ratio $\left(\rho=\mathrm{r}_{\text {small ion }} / \mathrm{r}_{\text {large ion }}<1\right)$ can have an effect on the ionic conductivities. Lower $\rho$ values exhibited higher ionic conductivities, which is attributed to the size and concentration of vacancies within the crystal [144-146], therefore, lower $\rho$ values have more voids due to large differences in the ionic radii. This allows for greater tunability of the IL, whereby new battery electrolytes can be considered with 
anions different to typical FSI or TFSI-based anions. Further work is required before new anions can be realized for battery applications, however, these results show that favorable thermal and ionic conductivity properties can be attained using unconventional anions.

To date, limited cathode and anode analysis has been carried out with only NCM, LFP, LTO and Li metal having exhibited compatibility with the $\mathrm{C}_{2}$ mpyr-based electrolytes. The primary cation/anion combination for $\mathrm{C}_{2}$ mpyr-based electrolytes is $\mathrm{C}_{2}$ mpyrFSI with little literature dedicated

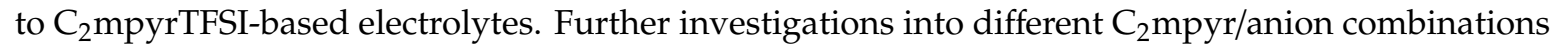
may lead to next generation battery electrolytes, however, in order to realize microbatteries, other pyrrolidinium-based ILs whose physiochemical properties have been thoroughly characterized need to be investigated.

\section{5. $N$-propyl- $N$-methylpyrrolidinium $\left(\mathrm{C}_{3} \mathrm{mpyr}\right)$-Based ILs}

Characterization of $N$-propyl- $N$-methylpyrrolidinium ( $C_{3}$ mpyr)-based ILs have been carried out by many research groups to determine the physiochemical properties of the IL with various anions $[147,148]$. The biodegradability and solubility of $\mathrm{C}_{3}$ mpyr-based ILs, and other pyrrolidinium-based ILs have also been investigated [149]. Thermal stability analysis has been carried out using commercial electrode materials (NCM, LFP, graphite, etc.) with LiFSI salt in $\mathrm{C}_{3}$ mpyrFSI electrolytes [150]. In addition to thermal stability, the total heat generated by the electrode was determined at various states of charge [150]. This study also showed that certain cathode and anode materials might undergo exothermic reactions at different temperatures, therefore, indicating the need to select the correct electrode material combinations for high temperature applications. The characterization of $C_{3}$ mpyr-based electrolytes also extends to its compatibility with different types of separators [151,152], particularly when Li metal anodes are utilized. The long-term cyclability of Li metal based cells is affected by the separator and small pore sizes $(0.06 \mu \mathrm{m})$ can prevent short circuits by inhibiting Li dendrite penetration of the separator [152]. Further information regarding different separator materials can be found in the review by Francis et al. [151].

\subsection{Liquid Electrolyte}

\subsection{1. $\mathrm{C}_{3}$ mpyrFSI/Cathode Compatibility}

Compatibility with various cathode and anode materials were shown in $\mathrm{C}_{3}$ mpyr-based electrolytes. In some cases, the $C_{3}$ mpyr-based electrolytes were utilized as an interlayer [153], however much of the research has focused on its use as an electrolyte. Two cation/anion combinations have been extensively investigated, namely, $\mathrm{C}_{3}$ mpyrFSI and $\mathrm{C}_{3}$ mpyrTFSI. For the conventional cathode materials such as NMC and LFP electrodes, analysis studies have been carried out primarily with $\mathrm{C}_{3}$ mpyrFSI and either LiTFSI or LiFSI salt. NMC electrodes have exhibited electrochemical performances comparable to organic electrolytes such as 1.0 $\mathrm{M} \mathrm{LiPF}_{6}$ in EC:DEC, (1:1) particularly at low C-rates [154].

Much like the NMC electrodes, LFP electrodes have also been investigated with $\mathrm{C}_{3}$ mpyrFSI-based electrolytes. For example, Lewandowski et al. [155] reported that the combination of $C_{3}$ mpyrFSI and $0.5 \mathrm{~mol} \mathrm{~kg}{ }^{-1}$ LiTFSI has been shown to work effectively as an electrolyte solution with a metallic lithium anode and LFP cathode. Even at a $4 \mathrm{C}$ rate, a discharge capacity of $110 \mathrm{mAh} \mathrm{g}^{-1}$ was obtained at $50{ }^{\circ} \mathrm{C}$, which shows the excellent cyclability of the $\mathrm{C}_{3}$ mpyrFSI electrolyte with the LFP cathode (Figure 3). 

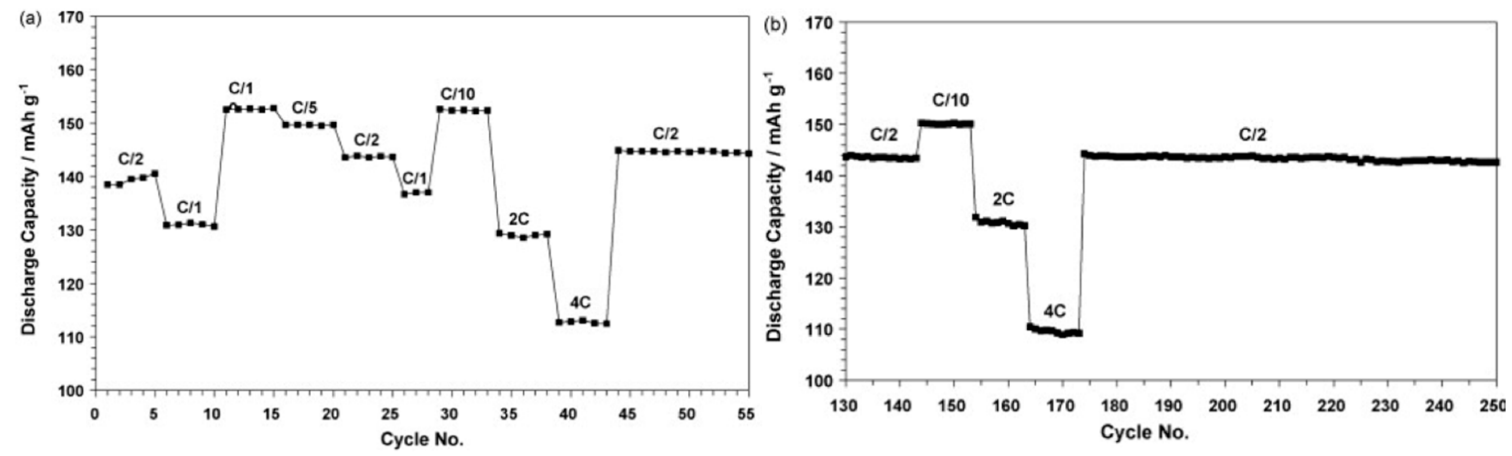

Figure 3. Cycling performance of Li|C $\mathrm{C}_{3}$ mpyrFSI-LiTFSI $\left(0.5 \mathrm{~mol} \mathrm{~kg}^{-1}\right) \mid \mathrm{LiFePO}_{4}$ cell at indicated discharge rates (at $50{ }^{\circ} \mathrm{C}$ ) for: (a) cycles 1-55 and (b) cycles 130-250. Charging rate is constant at C/10. Reprinted with permission from Lewandowski et al. [155].

\subsection{2. $\mathrm{C}_{3}$ mpyrTFSI and $\mathrm{C}_{3}$ mpyrFSI Electrolyte Mixtures}

Electrolyte mixtures consisting of $\mathrm{C}_{3}$ mpyrTFSI and $\mathrm{C}_{3}$ mpyrFSI have been investigated with NMC and LFP electrodes, whereby different conducting salts were utilized. In the case of NMC, the salt was LiTFSI and the optimum ratio of $C_{3}$ mpyrTFSI: $C_{3}$ mpyrFSI was determined to be $3: 6$ [156]. When LiFSI salt is utilized the optimum ratio of $C_{3}$ mpyrTFSI: $C_{3}$ mpyrFSI was determined to be 1:1 with LFP electrodes [157]. Due to the different properties of the conducting salts, the optimum ratios were chosen based on a compromise between fast ion transport properties, electrochemical/thermal stability, good film forming ability and cost [156]. Huang et al. [157] showed that the ternary electrolyte exhibited the best long-term cyclability when compared to its binary analogues: $0.5 \mathrm{M} \mathrm{LiFSI}$ in $\mathrm{C}_{3}$ mpyrFSI, $0.5 \mathrm{M}$ LiTFSI in $\mathrm{C}_{3}$ mpyrTFSI and $0.5 \mathrm{M} \mathrm{LiFSI} \mathrm{in} \mathrm{C}_{3}$ mpyrTFSI at room temperature, and sub-zero temperatures. This paves the way for low-temperature application electrolytes. Further work to optimize the ratio of $\mathrm{C}_{3}$ mpyrTFSI to $\mathrm{C}_{3} \mathrm{mpyrFSI}$, could lead to improvements in the electrode capacity obtained at both elevated and low temperatures, for binary mixtures such as those tested by Lewandowski et al. [155] with higher electrode capacities at C-rates such as $4 \mathrm{C}$.

\subsection{3. $\mathrm{C}_{3}$ mpyrTFSI/Cathode Compatibility}

The studies described above are for FSI-based electrolytes, however analysis of other cathode materials is focused primarily on $\mathrm{C}_{3}$ mpyrTFSI-based electrolytes. The results obtained in this electrolyte are promising as the electrodes exhibit high electrode capacities and coulombic efficiencies. One such example is a composite cathode material: $0.3 \mathrm{Li}_{2} \mathrm{MnO}_{3}-0.7 \mathrm{LiMn}_{1.5} \mathrm{Ni}_{0.5} \mathrm{O}_{4}$ [158], whereby the IL-based electrolyte exhibited a superior performance when compared to organic based electrolytes, $332 \mathrm{mAh} \mathrm{g}^{-1}$ and $310 \mathrm{mAh} \mathrm{g}^{-1}$, respectively. Even at high current densities such as $750 \mathrm{~mA} \mathrm{~g}^{-1}$ the IL outperformed the organic electrolyte due to the mitigation of Mn dissolution. Nickel sulphide, has also attracted a lot of attention due to its high theoretical capacity $\left(590 \mathrm{mAh} \mathrm{g}^{-1}\right.$ for NiS, and $462 \mathrm{mAh} \mathrm{g}^{-1}$ for $\mathrm{Ni}_{3} \mathrm{~S}_{2}$ ) [159]. The NiS-Ni $\mathrm{N}_{7}$ material exhibited the best $\mathrm{CV}$ performance when utilized with $1 \mathrm{M}$ LiTFSI in $\mathrm{C}_{3}$ mpyrTFSI as stable cycling was observed in addition to higher electrode capacities $\left(450 \mathrm{mAh} \mathrm{g}^{-1}\right)$ when compared to an organic electrolyte $\left(200 \mathrm{mAh} \mathrm{g}^{-1}\right)$. Studies with vanadium pentoxide $\left(\mathrm{V}_{2} \mathrm{O}_{5}\right)$ have also indicated promising electrochemical performances as different morphologies including nanoribbon, nanowire, microflake and commercial powder were investigated with $\mathrm{C}_{3}$ mpyrTFSI [160]. Each morphology yielded greater specific capacity when compared to a conventional organic electrolyte $\left(1 \mathrm{M} \mathrm{LiPF}_{6}\right.$ in EC/DMC (1:1)).

\subsubsection{Anode Compatibility}

Conventional anode materials such as graphite $[156,161,162]$ are compatible with the $C_{3}$ mpyr-based ILs. Alternative higher energy density anode materials such as $\mathrm{Si}$ have also been investigated. Recent research is focused on coated or doped Si films to improve the cyclability of the Si electrodes by 
buffering or mitigating the expansion and contraction effects upon cycling with Li. Superior reversible cycling of graphene coated Si nanoparticles in $\mathrm{C}_{3}$ mpyrFSI-based electrolyte when compared to the organic electrolytes was shown by Park et al. [163]. The electrodes cycled with the IL electrolyte maintained a capacity of $1800 \mathrm{mAh} \mathrm{g}^{-1}$ after 200 cycles, while capacities less than $500 \mathrm{mAh} \mathrm{g}^{-1}$ were obtained in the organic electrolyte. A comparison of doped and undoped-Si in $1 \mathrm{M}$ LiFSI and $\mathrm{C}_{3}$ mpyrFSI electrolytes determined that P-doping led to reduced vertical electrode expansion during cycling with the IL electrolyte as shown in Figure 4 [164], with superior cyclability (>1400 cycles) when compared to its counterpart within an organic electrolyte. The reduction in vertical expansion is attributed to the film's preference for horizontal expansion due to the film being perpendicularly pressed to the $\mathrm{Cu}$ current collector by the separator in the coin cell.

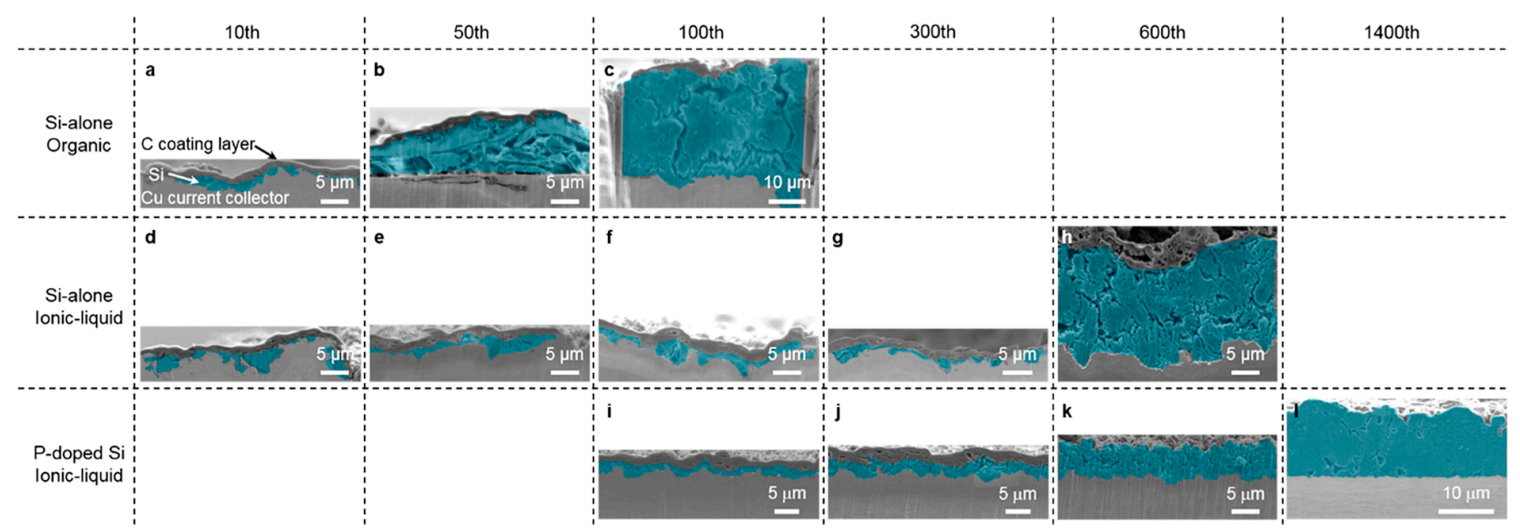

Figure 4. Cross-sectional SEM images of lithiated Si active material layers with a charge capacity limit of $1000 \mathrm{mAh} \mathrm{g}^{-1}$. The blue colored area indicates $\mathrm{Si}$, while the topmost layer is a carbon coating. Reprinted with permission from Domi et al. [164]. Copyright 2019 American Chemical Society.

The choice of IL anion can affect the electrochemical performance of P-doped Si electrodes. In $\mathrm{C}_{3}$ mpyrFSI-based electrolytes stable cycling for over 1400 cycles, with a discharge capacity of $1000 \mathrm{mAh} \mathrm{g}^{-1}$ was reported, while the TFSI-counterpart could only maintain stability for 600 cycles [165]. The rate capability of the electrode is also affected by the anion choice as electrodes with $\mathrm{C}_{3}$ mpyrTFSI-based ILs experience a drop in capacity at rates above 2 C, while the FSI-based IL maintains $1000 \mathrm{mAh} \mathrm{g}^{-1}$ regardless of the rate. Nguyen et al. [166] investigated Si-Cu anodes with capacities of $1500 \mathrm{mAh} \mathrm{g}^{-1}$ over 200 cycles.

\subsubsection{Full Cell Studies}

Despite the results described above to date no full cell utilizing a Si anode, NMC or LFP cathode and $\mathrm{C}_{3}$ mpyrFSI electrolyte has been reported. A full cell containing NMC and graphite has been investigated [161] where electrochemical impedance analysis was utilized to determine the optimum LiFSI: $C_{3}$ mpyrFSI ratio of 40:60, which offered the lowest overall cell resistance, in addition to the highest ionic conductivity. From the impedance analysis it was determined that the maximum cycling rate achievable by the cell was $0.77 \mathrm{C}$.

\subsection{Polymer Gel Analogue}

There has been extensive research carried out on $\mathrm{C}_{3}$ mpyr-based polymer gel electrolytes where the two common cathode materials investigated are NMC and LFP. Polymer gel electrolytes that have shown compatibility with NMC electrodes consist of either $C_{3}$ mpyrFSI or $C_{3}$ mpyrTFSI. Nair et al. [167] recorded an ionic conductivity of $10^{-4} \mathrm{~S} \mathrm{~cm}^{-1}$ at room temperature for the polymer gel, which is one order of magnitude lower than the liquid analogue, which they attributed to the addition of the UV crosslinkers, inactive components within the gel. 


\subsubsection{Polymers Incorporating PVDF-HFP}

By utilizing polymer materials such as poly(vinylidene fluoride-co-hexafluoropropylene) (PVDF-HFP), polymer gels with high ionic conductivities such as $3.9 \times 10^{-3} \mathrm{~S} \mathrm{~cm}^{-1}$ at $30^{\circ} \mathrm{C}$ can be obtained as reported by Singh et al. [168]. Gels consisting of PVDF-HFP, $20 \mathrm{wt} \%$ LiTFSI and $\mathrm{C}_{3} \mathrm{mpyrFSI}$ were utilized, and higher electrode capacities were obtained at a C/10 rate, where temperatures of $25^{\circ} \mathrm{C}$ were employed $\left(180 \mathrm{mAh} \mathrm{g}^{-1}\right.$ vs. $\left.100 \mathrm{mAh} \mathrm{g}^{-1}\right)$ when compared to the cross-linked polymer gel synthesized by Nair et al. [167]. These results show that the incorporation of organic electrolytes within the polymer gel electrolyte is not necessary to achieve high ionic conductivities and electrode capacities. Adjusting the polymer matrix from PVDF-HFP to polyethylene oxide (PEO) can lead to significant changes in the electrochemical properties of the gel.

\subsubsection{Polymers Incorporating PEO}

Gupta et al. [169] utilized a PEO matrix with $20 \mathrm{wt} \%$ LiFSI salt and $C_{3}$ mpyrFSI, and the highest ionic conductivity of the synthesized polymer gels was $1.14 \times 10^{-5} \mathrm{~S} \mathrm{~cm}^{-1}$, which is lower than PVDF-HFP-based polymer gels. When tested with LFP electrodes, it was determined that the interfacial kinetics were more favorable with the polymer gel electrolyte when a graphene oxide coat is applied to LFP, thus resulting in higher electrode capacities. Guerfi et al. [170] immersed LFP and Li metal electrodes in $\mathrm{C}_{3}$ mpyrFSI and $0.7 \mathrm{M}$ LiFSI with $5 \mathrm{wt} \%$ polymer (ether based). Heating the cell under vacuum enabled electrolyte penetration of the LFP electrode, which allowed for the formation of a stable SEI layer when cycled with Li. This resulted in capacities that were close to the rated capacity for all rates up to $2 \mathrm{C}$ within an LFP/graphite full cell.

\subsubsection{Polymers with Coagulation or Cross-Linking}

Numerous groups have studied $C_{3}$ mpyrTFSI-based polymer gel using a variety of methods such as cross-linking [171] and coagulation [172]. Cross-linked polymer gel electrolytes such as that synthesized by Li et al. [171] have shown promising results with high electrode capacities and coulombic efficiencies $\left(151.9 \mathrm{mAh} \mathrm{g}^{-1}\right.$, and a coulombic efficiency of $87.9 \%$ ) obtained at room temperature. After 80 cycles, an electrode capacity of $131.9 \mathrm{mAh} \mathrm{g}^{-1}$ was retained, which corresponds to a $13 \%$ capacity drop over the course of 80 cycles. These figures are impressive as elevated temperatures $\left(>40^{\circ} \mathrm{C}\right)$ are typically utilized in the case of other polymer gel electrolytes in order to achieve high electrode capacities.

Coagulation synthesis methods are beneficial for the formation and control of porous membranes as shown by Yang et al. [172]. By controlling the amount of time spent in the coagulation bath, the porosity of the polymer gel electrolyte can be tailored as shown in Figure 5. The porosity of the polymer gel greatly affected its ionic conductivity, with the highest values obtained for the polymer gels, which spent $5 \mathrm{~min}$ or less within the coagulation bath (more porous). The electrochemical tests carried out by Yang et al. [172] boasted an improved electrochemical performance when compared to the cross-linked polymer gel synthesized by Li et al. [171] as an electrode capacity of $150 \mathrm{mAh} \mathrm{g}^{-1}$ was maintained over the course of 200 cycles with no substantial capacity fade occurring over the course of 200 cycles at room temperature. Electrode capacities above $100 \mathrm{mAh} \mathrm{g}^{-1}$ were maintained even at high C-rates such as $3 \mathrm{C}$. Elevated temperatures further enhanced the electrochemical performance of the cell as electrode capacities higher than $150 \mathrm{mAh} \mathrm{g}^{-1}$, with minimal capacity fade observed over the course of 200 cycles. A similar trend was noted previously with $C_{3}$ mpyrFSI-based polymer gels, whereby the cross-linked polymer gel yielded poorer electrochemical performances when compared to the PVDF-HFP-based polymer gels. 

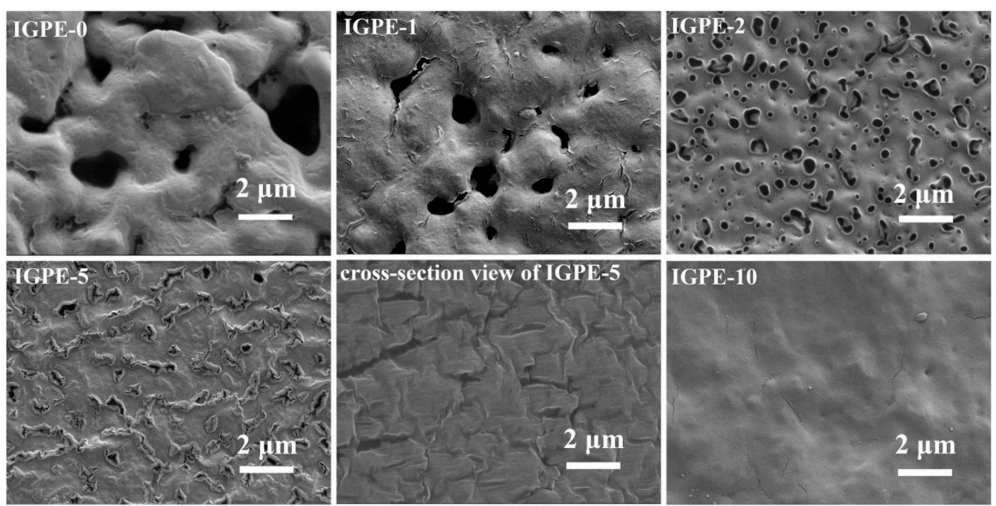

Figure 5. SEM images of different IGPE-X membranes, where the $X$ refers to the length of time (in minutes) the gel spent in the coagulation bath. Reprinted with permission from Yang et al. [172].

\subsubsection{Polymers Incorporating Inorganic Materials}

The utilization of inorganic materials within polymer gels has been investigated to enhance the mechanical strength, while improving ion transport properties. Kim et al. [173] investigated amine functionalized boron nitride nanosheets (AFBNNS) as an additive within a $\mathrm{C}_{3}$ mpyrTFSI-based polymer gel. The addition of AFBNNS led to an improvement in the mechanical strength and thermal stability, in addition to yielding high $\mathrm{Li}^{+}$transference numbers of $0.12-0.23$, which are comparable to Yang et al. [172]. The electrochemical performance of LFP with the AFBNNS-based polymer gel electrolyte offers similar performances to Yang et al. [172], as high electrode capacities $142.4 \mathrm{mAh} \mathrm{g}^{-1}$ and $132.8 \mathrm{mAh} \mathrm{g}^{-1}$ were obtained at $0.1 \mathrm{C}$ and $0.2 \mathrm{C}$, respectively. Without the presence of the AFBNNS, rapid capacity loss was observed over 60 cycles for the liquid and polymer gel electrolytes. Similarly, for NCM and LCO cathode materials, the electrochemical performance was greatly enhanced when AFBNNS-based polymer gel electrolytes were utilized. At $80^{\circ} \mathrm{C}$ the LFP cell was capable of delivering a high discharge capacity of $162.1 \mathrm{mAh} \mathrm{g}^{-1}$ at the 2 nd cycle with $91.3 \%$ of specific capacity retained after the 50th cycle (Figure 6).
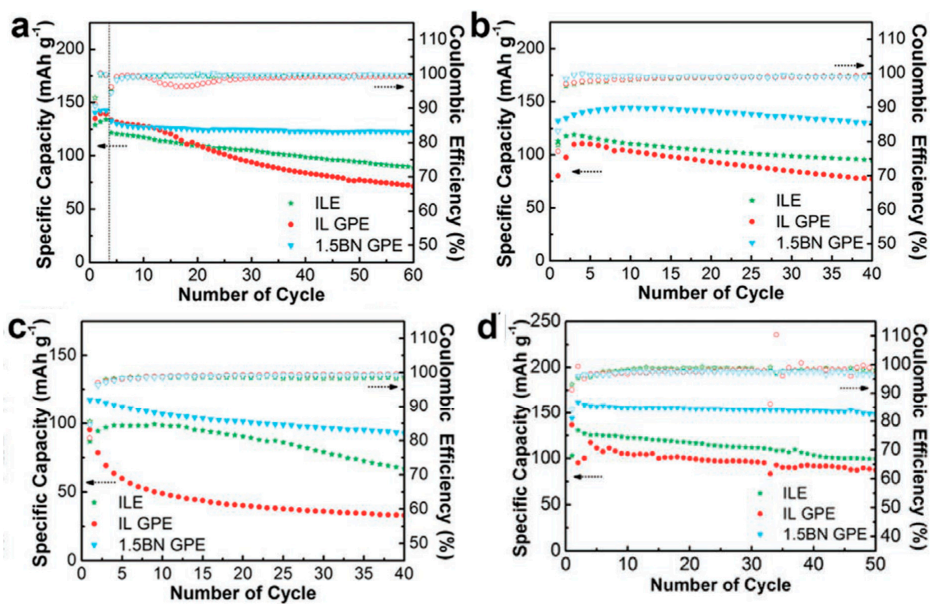

Figure 6. Cycling stability at $0.2 \mathrm{C}$ of (a) LFP|Li cell, (b) NCM|Li cell, (c) LCO|Li cell and (d) cycling stability at $0.5 \mathrm{C}$ of $\mathrm{LFP} \mid \mathrm{Li}$ cell at $80^{\circ} \mathrm{C}$ with liquid, polymer and $\mathrm{BN}$-functionalized-polymer versions of $\mathrm{C}_{3}$ mpyrTFSI. Adapted with permission from Kim et al. [173].

$\mathrm{Al}_{2} \mathrm{O}_{3}$ has been investigated as a protective agent for $\mathrm{Li}$ metal and has mainly been studied from the perspective of surface coating and plating technologies. Wen et al. [174] utilized a leaf-like $\mathrm{Al}_{2} \mathrm{O}_{3}$ skeleton to form a quasi-solid-state electrolyte comprising of $1 \mathrm{M} \mathrm{LiTFSI}$, and $\mathrm{C}_{3}$ mpyrTFSI. In that instance the $\mathrm{Al}_{2} \mathrm{O}_{3}$ skeleton absorbed the ionic liquid, which allowed for improved ionic conductivity, in addition to promoting the migration of $\mathrm{Li}^{+}$both in the bulk and at the interface. When coupled with 
LFP/Li full cell, the initial discharge capacity obtained was $140.7 \mathrm{mAh} \mathrm{g}^{-1}$ of which $95.6 \%$ was retained after 100 cycles at $30^{\circ} \mathrm{C}$ and $0.1 \mathrm{C}$.

$\mathrm{C}_{3}$ mpyr-based electrolytes exhibited their versatility as they could be utilized as liquid or solid-state electrolytes (polymer gel). The cation/anion combination, $\mathrm{C}_{3} \mathrm{mpyrFSI}$, has proven to be a popular choice among research groups when utilized as a liquid electrolyte as it has compatibility with high-energy density materials such as $\mathrm{Si}$, which is beneficial for the miniaturization of energy storage devices. However, when utilized as a polymer gel, the more popular cation/anion combination is $\mathrm{C}_{3}$ mpyrTFSI. The polymer gel electrolyte analysis has been limited mostly to LFP and Li metal cells, therefore further analysis is required in order to determine the compatibility of $\mathrm{C}_{3}$ mpyrTFSI-based polymer gels with high-energy dense materials.

\section{6. $N$-butyl- $N$-methylpyrrolidinium $\left(\mathrm{C}_{4} \mathrm{mpyr}\right)$-Based ILs}

Similarly to $\mathrm{C}_{3}$ mpyr-based ILs, there has been extensive characterization of 1-butyl-1methylpyrrolidinium ( $\mathrm{C}_{4} \mathrm{mpyr}$ )-based ILs [147], for example, Fernández-Miguez et al. [115] investigated high $(1.5 \mathrm{M})$ and low $(0.1 \mathrm{M})$ LiTFSI salt concentrations within $\mathrm{C}_{4}$ mpyrTFSI ILs. It was determined that LiTFSI salt addition leads to higher densities than that of the pure IL, but it decreased linearly with increasing temperature. Conductivity values for pure $\mathrm{C}_{4}$ mpyrTFSI and with various LiTFSI salt concentrations $(0.1 \mathrm{M}, 0.5 \mathrm{M}, 1 \mathrm{M}$ and $1.5 \mathrm{M})$ were reported. The ionic conductivity decreased with increasing LiTFSI salt concentration, and the authors determined the conductivity values for each concentration across a range of temperatures. Other characterization tests carried out have been mentioned in previous pyrrolidinium subsections $[148,149]$. Another important characterization carried out recently is the degradation of $\mathrm{C}_{4}$ mpyrTFSI in the presence of Li metal at room temperature (Figure 7) recently studied by Preibisch et al. [175]. They identified a new degradation product $\mathrm{N}$-butyl- $\mathrm{N}$-methyl-N-but-3-eneamine, which was previously unreported and suggested that it participates in the formation of an organic layer at the surface of Li metal. This degradation product stems from the $\mathrm{C}_{4}$ mpyr cation, rather than from the anion, which typically dominates in SEI layer formation. The presence of $N$-butyl- $N$-methyl- $N$-but-3-eneamine paves the way to the formation of potentially polymerized species that could "bind" the inorganic fraction of the decomposition layer and provide elastomeric properties to accommodate changes in the electrode volume. By harnessing the elastomeric properties of $\mathrm{N}$-butyl- $\mathrm{N}$-methyl- $\mathrm{N}$-but-3-eneamine as an additive, the realization of group IV element anodes could be advanced providing the electrode volume changes can be mitigated due to the "elastic" SEI layer.

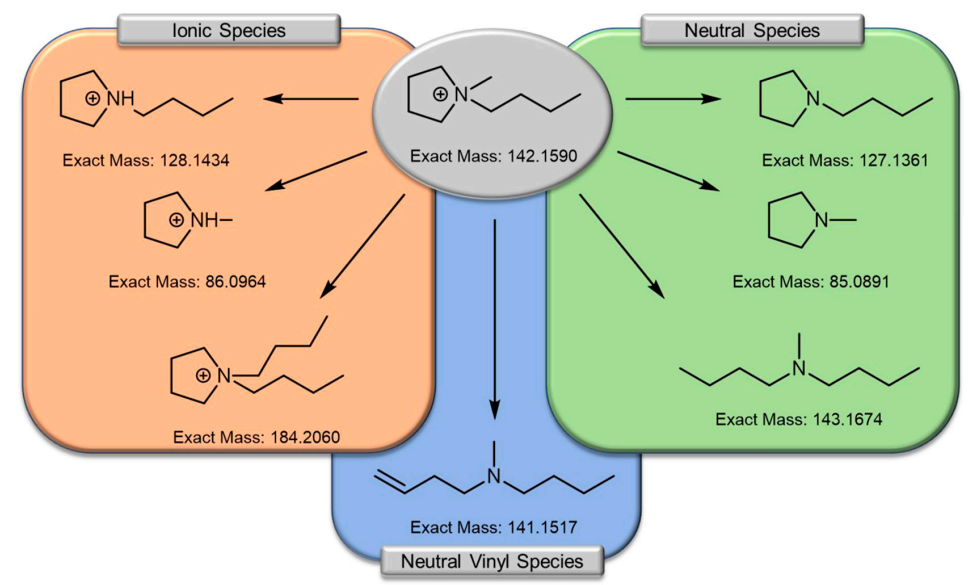

Figure 7. Graphical summary of the range of ionic and neutral decomposition species of $\mathrm{C}_{4}$ mpyr-cation. The ionic species (orange box) were identified by Pyschik et al. [176,177] while Kroon et al. [178] confirmed the presence of the neutral species (green box). The neutral vinyl species was identified by Preibisch et al. [175] Reprinted with permission from Preibisch et al. [175]. Copyright 2020 American Chemical Society. 


\subsection{Liquid Electrolyte}

\subsubsection{TFSAM-Anion Studies}

The most commonly studied $\mathrm{C}_{4}$ mpyr-based ILs are based on the TFSI ${ }^{-}$and FSI $^{-}$anions. This is due to their superior film-forming abilities on the surface of the Li metal, which enable uniform Li deposition/dissolution with high cycling efficiencies, and no Li dendritic formation as reported by Grande et al. [179]. This study highlighted the effectiveness of $\mathrm{Li}^{+}$mobility within $\mathrm{C}_{4}$ mpyr-based ILs, which is why extensive research has been carried out using $\mathrm{C}_{4}$ mpyr-based electrolytes with those and trifluoromethanesulfonyl-N-cyanoamide (TFSAM) anions. Recently, TFSAM has been utilized as an anion due to its ability to inhibit crystallization over a broader temperature range when compared to TFSI [180]. The asymmetric TFSAM anion, promotes single $\mathrm{Li}^{+}$hopping due to higher structural diffusion that occurs as the LiTFSAM salt concentration increases [180]. Electrolytes containing TFSAM anions, have not been widely investigated, and present a potential area for analysis, however, $\mathrm{C}_{4}$ mpyrTFSAM compatibility with NCM electrodes has been investigated by Hoffknecht et al. [181]. Cycling at $40{ }^{\circ} \mathrm{C}$ was carried out and high cycle efficiencies were obtained from the initial cycle, with a coulombic efficiency of $92.6 \%$. Over $90 \%$ of the initial capacity was retained in the 30th cycle, however, the long-term stability of the cell was not described, and requires further investigation.

\subsubsection{Interlayers}

The $\mathrm{C}_{4}$ mpyr anion combination, with TFSI and FSI anions, has again been extensively studied, not only as electrolytes, but also as electrode binders and interlayers. Liquid interlayers have been investigated at both the anode and cathode sides using $\mathrm{C}_{4}$ mpyrFSI and LiTFSI salt. Pervez et al. [182] used it as an interlayer between the $\mathrm{Li}_{6.5} \mathrm{La}_{2.5} \mathrm{Ba}_{0.5} \mathrm{ZrNbO}_{12}$ (LLZO) solid-state electrolyte and the electrodes. Due to the liquid-like nature of the IL, it fills the voids between the electrode and electrolytes, and improves the interfacial properties of LLZO with both the cathode and anode. The interfacial resistance between the Li metal and LLZO electrolyte is significantly decreased upon addition of the IL interlayer. This allows for the realization of higher electrode capacities than for cells without the interlayer. Similarly, low interfacial resistance was observed for the IL interlayer in contact with LFP. Improved interfacial kinetics was observed when $\mathrm{C}_{4}$ mpyr-based ILs were used as an electrode binder. $\mathrm{C}_{4}$ mpyrTFSI and LiTFSI were confined within a PEO matrix to form a glue-like polymer, which then penetrated sheet-type composite NCM electrodes to act as an ion-conductive binding material, which effectively increased the effective contact area between the electrode components (Figure 8) [183]. This resulted in lower overpotentials due to the higher active area, whereby the cell achieved $92 \%$ of the capacity obtained by the NCM electrode in a conventional organic electrolyte [184].

\subsubsection{Cosolvents}

$\mathrm{C}_{4}$ mpyrTFSI-based electrolytes have been studied as cosolvents with conventional organic electrolytes. These electrolytes have been studied with anode materials such as graphite and Si. For instance, Balducci et al. [185] utilized $\mathrm{C}_{4}$ mpyrTFSI as a cosolvent with LiTFSI salt, and EC/DEC/DMC $(1: 1: 1 w / w)$, and observed stable cycling over the course of 50 cycles. The stability of the electrode with the electrolyte lead to minimal capacity fade over 50 cycles, and a coulombic efficiency close to $100 \%$ during cycling. These cosolvent tests showed promising results when utilized with high energy dense materials such as $\mathrm{Si}$, as Balducci et al. [185] obtained stable discharge capacities of $550 \mathrm{mAh} \mathrm{g}^{-1}$ at $0.1 \mathrm{C}$, with minimal capacity fade observed across 100 cycles. The electrolyte utilized $\mathrm{C}_{4}$ mpyrTFSI as a cosolvent with EC:DEC:DMC (1:1:1), and LiTFSI salt. 

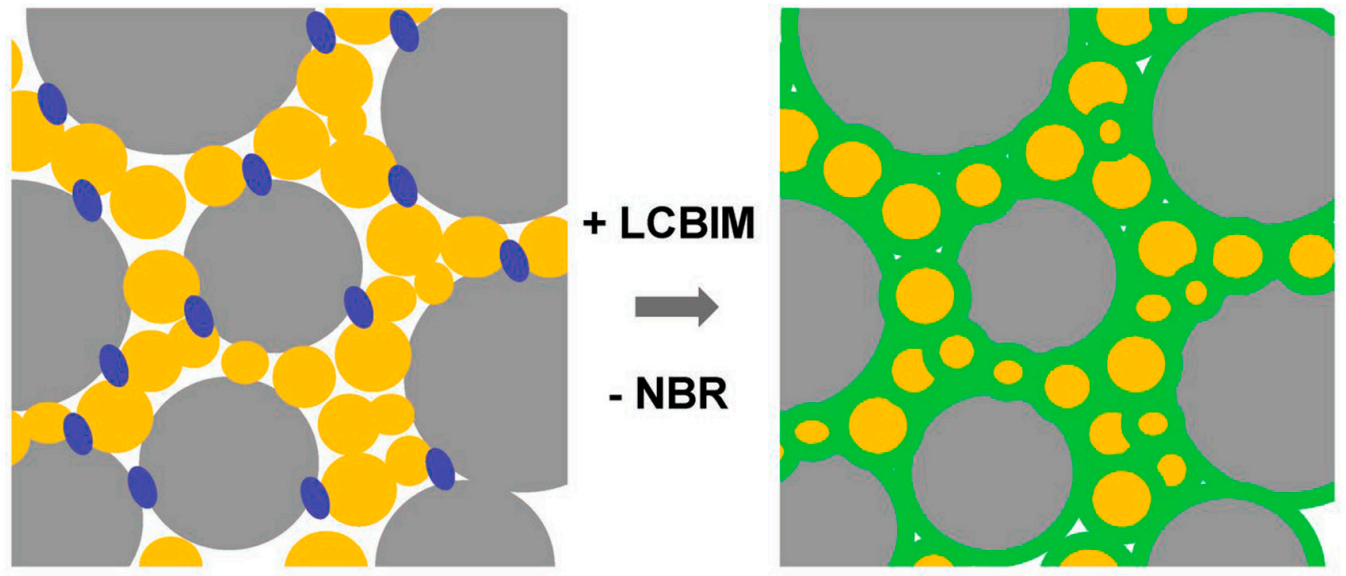

\section{Cathode material} sulfide solid electrolyte

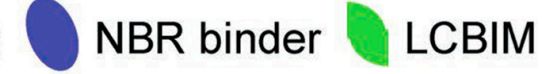

Figure 8. Schematic diagram representing the microstructure of the composite electrodes with polymer gel electrolyte (LCBIM), showing that LCBIM improves the interfacial contact area with conductive and adhesive properties. Carbon additives included in the composite electrode are not shown. Reprinted with permission from Cho et al. [183].

\subsubsection{Sole Electrolyte}

To limit the amount of organic solvents in the electrolyte, $\mathrm{C}_{4}$ mpyr-based ionic liquid electrolytes were investigated. In liquid form, the most commonly studied $\mathrm{C}_{4}$ mpyr-based IL is $\mathrm{C}_{4}$ mpyrTFSI with LiTFSI salt. Utilization of an ionic liquid electrolyte can lead to lower electrode-wettability and lower $\mathrm{Li}^{+}$transport number as observed by Di Lecce et al. [186]. They investigated the electrochemical performance of the olivine cathode $\mathrm{LiFe}_{0.5} \mathrm{Mn}_{0.5} \mathrm{PO}_{4}$ and determined that the reversible exchange of $0.6 \mathrm{Li}$ could be obtained in $\mathrm{C}_{4}$ mpyrTFSI, which corresponds to an electrode capacity of $100 \mathrm{mAh} \mathrm{g}^{-1}$. In conventional organic electrolytes, Li exchange was significantly higher at 0.7 or greater. However, this is considered a trade-off for the increased intrinsic safety of the IL electrolytes. In addition, utilization of higher operating temperatures can lead to improved performances, where the interfacial resistance decreased with increasing temperature. As the temperature increased, the electrode-wettability increased, therefore paving the way for high electrode capacities. Recently, McGrath et al. [187] reported compatibility of electrodeposited $\mathrm{V}_{2} \mathrm{O}_{5}$ cathode materials with $\mathrm{C}_{4}$ mpyrTFSI-based electrolytes and Li metal anodes. Amorphous and crystalline $\mathrm{V}_{2} \mathrm{O}_{5}$ materials were investigated with $0.5 \mathrm{M} \mathrm{LiTFSI}$ in $\mathrm{C}_{4}$ mpyrTFSI and $3 \mathrm{wt} \% \mathrm{VC}$ in $0.5 \mathrm{M}$ LiTFSI in $\mathrm{C}_{4}$ mpyrTFSI. Superior cycling was observed for the crystalline materials, as coulombic efficiencies close to $100 \%$ were attained across all scan rates, while the amorphous material's coulombic efficiency was scan rate dependent. Additive analysis (VC) with the crystalline material exhibited superior cycling than for its additive-free counterpart, as greater electrode capacities were attained even at $10 \mathrm{C}$ (VC-containing: $75 \mathrm{mAh} \mathrm{g}^{-1}$ versus VC-free: $30 \mathrm{mAh} \mathrm{g}^{-1}$ ). In addition, up to 400 cycles was exhibited by the $\mathrm{V}_{2} \mathrm{O}_{5} / \mathrm{Li}$ cell with no evidence of electrode deterioration even at prolonged cycling at high $\mathrm{C}$-rates such as $5 \mathrm{C}$.

A comparison of the electrochemical performances of $\mathrm{C}_{4}$ mpyrTFSI- and $\mathrm{C}_{4}$ mpyrFSI-based electrolytes has been carried out on both anode and cathode materials. Elia et al. [39] reported that $\mathrm{C}_{4} \mathrm{mpyrFSI}$ showed the greatest promise with LFP electrodes as it yielded the highest electrode capacity at $25 \mathrm{~mA} \mathrm{~g}^{-1}$ and $250 \mathrm{~mA} \mathrm{~g}^{-1}$ (Figure 9). The electrode capacity obtained at $250 \mathrm{~mA} \mathrm{~g}^{-1}$ in $\mathrm{C}_{4}$ mpyrFSI was similar to that obtained at $25 \mathrm{~mA} \mathrm{~g}^{-1}$. The TFSI-based electrolyte, by comparison, gave poorer rate performance and capacities below $80 \mathrm{mAh} \mathrm{g}^{-1}$ were obtained at a current density of at $250 \mathrm{~mA} \mathrm{~g}^{-1}$. 


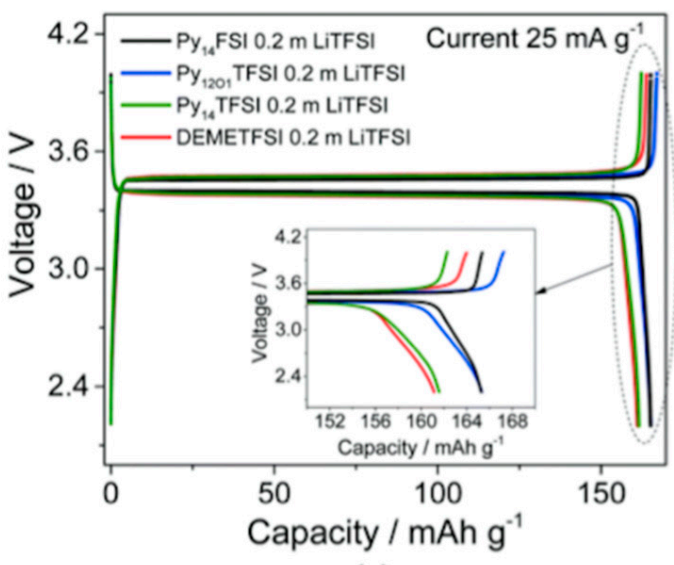

(a)

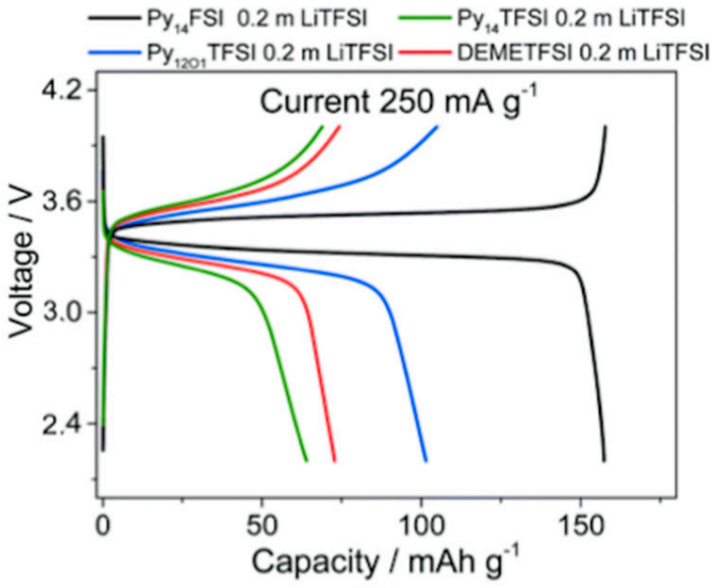

(b)

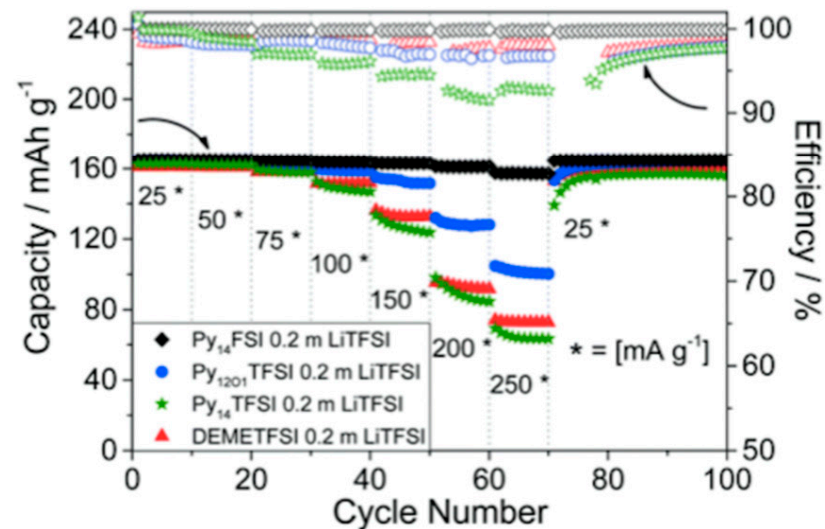

(c)

Figure 9. Li|IL|LFP cells galvanostatically cycled at (a) $25 \mathrm{~mA} \mathrm{~g}^{-1}\left(0.12 \mathrm{~mA} \mathrm{~cm}{ }^{-2}\right)$, with inset reporting the magnification of the final part of the curves, and (b) $250 \mathrm{~mA} \mathrm{~g}^{-1}\left(1.2 \mathrm{~mA} \mathrm{~cm}^{-2}\right)$. (c) Cycling trend and columbic efficiency of the Li/IL/LFP cells at increasing currents. Voltage cut-offs were 2.2 and $4 \mathrm{~V}$. $\mathrm{Pyr}_{14}$ TFSI-LiTFSI (green), $\mathrm{Pyr}_{14}$ FSI-LiTFSI (black), $\mathrm{Pyr}_{1(2 \mathrm{o} 1)}$ TFSI-LiTFSI (blue) and DEME-TFSI-LiTFSI (red). All measurements were performed at $40^{\circ} \mathrm{C}$. Reprinted with permission from Elia et al. [39].

A similar trend was observed for anode materials such as Ge as the lower viscosity, higher ionic conductivity $\mathrm{C}_{4}$ mpyrFSI electrolyte enabled higher electrode discharge capacities to be obtained, $445 \mathrm{mAh} \mathrm{g}^{-1}$ vs. $260 \mathrm{mAh} \mathrm{g}^{-1}$ for $\mathrm{C}_{4}$ mpyrTFSI. Similar trends were observed with Si electrodes [188]. The difference in the electrochemical performance was attributed to the SEI layer formation on the electrode as the anions underwent different decomposition mechanisms upon electrochemical reduction at different rates. FSI anions rapidly released F-, forming LiF in the SEI, therefore suggesting the formation of an SEI layer comprised of small inorganic compounds. TFSI anions degrade to form different SEI layer products such as $-\mathrm{SO}_{2} \mathrm{CF}_{3}$ at a much slower rates than FSI counterparts [189]. The composition of the SEI layer can affect the chemical structure and morphology of the SEI layer and critically influence the safety, cycle life, power capability, side reactions and shelf life of Li-ion batteries. 


\subsection{Polymer Gel Analogue}

\subsection{1. $\mathrm{C}_{4}$ mpyrFSI-Based Polymers}

Despite the higher electrochemical performances in liquid form, the use of $\mathrm{C}_{4}$ mpyrFSI electrolytes with polymer matrices is not commonly studied. Kerner et al. [190] synthesized PIL-based electrolytes, where one set contained $\mathrm{C}_{4}$ mpyrTFSI, and another set contained $\mathrm{C}_{4}$ mpyrFSI. Both electrolytes tested with LFP yielded electrode discharge capacities above $140 \mathrm{mAh} \mathrm{g}^{-1}$ at $80{ }^{\circ} \mathrm{C}$ when $0.5 \mathrm{C}$ rate was utilized. The $\mathrm{C}_{4}$ mpyrFSI containing electrolyte yielded higher electrode capacities close to theoretical $\left(160 \mathrm{mAh} \mathrm{g}^{-1}\right)$ for C-rates up to $0.5 \mathrm{C}$. A similar trend to the liquid electrolytes was observed as the FSI-containing electrode yielded higher electrode capacities, however, high temperatures $\left(80{ }^{\circ} \mathrm{C}\right)$ were required for these high electrode capacities. By changing the PIL, Appetecchi et al. [191] synthesized films, which yielded LFP electrode capacities of $148 \mathrm{mAh} \mathrm{g}^{-1}$ (87\% of the nominal capacity) at $40^{\circ} \mathrm{C}$ and $\mathrm{C} / 20$.

\subsection{2. $\mathrm{C}_{4}$ mpyrTFSI-Based Polymers}

Simple polymer matrices such as PVDF-HFP, poly(ethylene carbonate) (PEC) and CMC have been investigated in addition to polymer gels, which consist of PILs. Kimura et al. [192] synthesized a polymer consisting of poly(ethylene carbonate) (PEC), LiTFSI, $\mathrm{C}_{4}$ mpyrTFSI and non-woven $\mathrm{SiO}_{2}$ fiber. It exhibited low ionic conductivity at room temperature $\left(10^{-7} \mathrm{~S} \mathrm{~cm}^{-1}\right)$ and is only suited for high temperature applications. At temperatures of $75^{\circ} \mathrm{C}$, stable cycling was obtained with low electrode polarization at a $\mathrm{C} / 15$ rate.

Kim et al. [193] synthesized an electrospun PVDF-HFP polymer membrane, which was then soaked in $1 \mathrm{M}$ LiTFSI and $\mathrm{C}_{4}$ mpyrTFSI. An uptake of $300 \%$ was observed, which is significantly higher than that reported for Celgard separators [194]. The soaked membrane exhibited ionic conductivity of $10^{-3} \mathrm{mS} \mathrm{cm}^{-1}$ at room temperature, with a Li transport number of 0.04 . Good reversibility and cyclability was observed at room temperature with LFP electrodes. Capacity retention of $92 \%$ and $69 \%$ was reported for the $0.1 \mathrm{C}$ and $1 \mathrm{C}$ rates after 55 cycles. The increase in electrode polarization at $1 \mathrm{C}$ suggests that this membrane was better suited to $\mathrm{C}$-rates below $1 \mathrm{C}$ to ensure stable, long-term cycling with minimal capacity loss.

An alternative to soaking a polymer membrane in the liquid IL is to encapsulate the ionic liquid in the PVDF-HFP matrix as reported recently by McGrath et al. [195]. The ionic liquid was encapsulated in the membrane and it resulted in free-standing flexible films, which exhibited ionic conductivities in the range of $7 \times 10^{-5}$ to $1.9 \times 10^{-3} \mathrm{~S} \mathrm{~cm}^{-1}$ at room temperature (Figure 10). Analysis with $\mathrm{V}_{2} \mathrm{O}_{5}$ electrodes coupled with Li metal anodes yielded promising results as 400 cycles was exhibited (Figure $10 \mathrm{~b}$ ) without capacity fade or short circuits developing, in addition, minimal capacity fade was observed when compared to its liquid counterpart ( 0.4 vs. $2.9 \%$ over 50 cycles at 5 C) [187]. After 400 cycles, the final $0.2 \mathrm{C}$ rate capacity was recovered in the PG-60 test to $125 \mathrm{mAh} \mathrm{g}^{-1}$ after cycling at $5 \mathrm{C}$, matching the initial $0.2 \mathrm{C}$ data, thus showing that that fast cycling did not lead to electrode deterioration. Its use with anode materials such as Ge has also been investigated [195]. Galvanostatic cycling analysis with Ge materials (Figure 10c,d) achieved average electrode capacities of $800 \mathrm{mAh} \mathrm{g}^{-1}$ at $0.2 \mathrm{C}$, with coulombic efficiencies greater than $99 \%$. Capacity recovery was also observed as the 71st to 80th capacity matched that of the initial capacity at $0.15 \mathrm{C}\left(900 \mathrm{mAh} \mathrm{g}^{-1}\right)$ following cycles at higher rates. Up to 90 cycles was achieved with no capacity fade, which indicates a buffering effect of the polymer gel. 

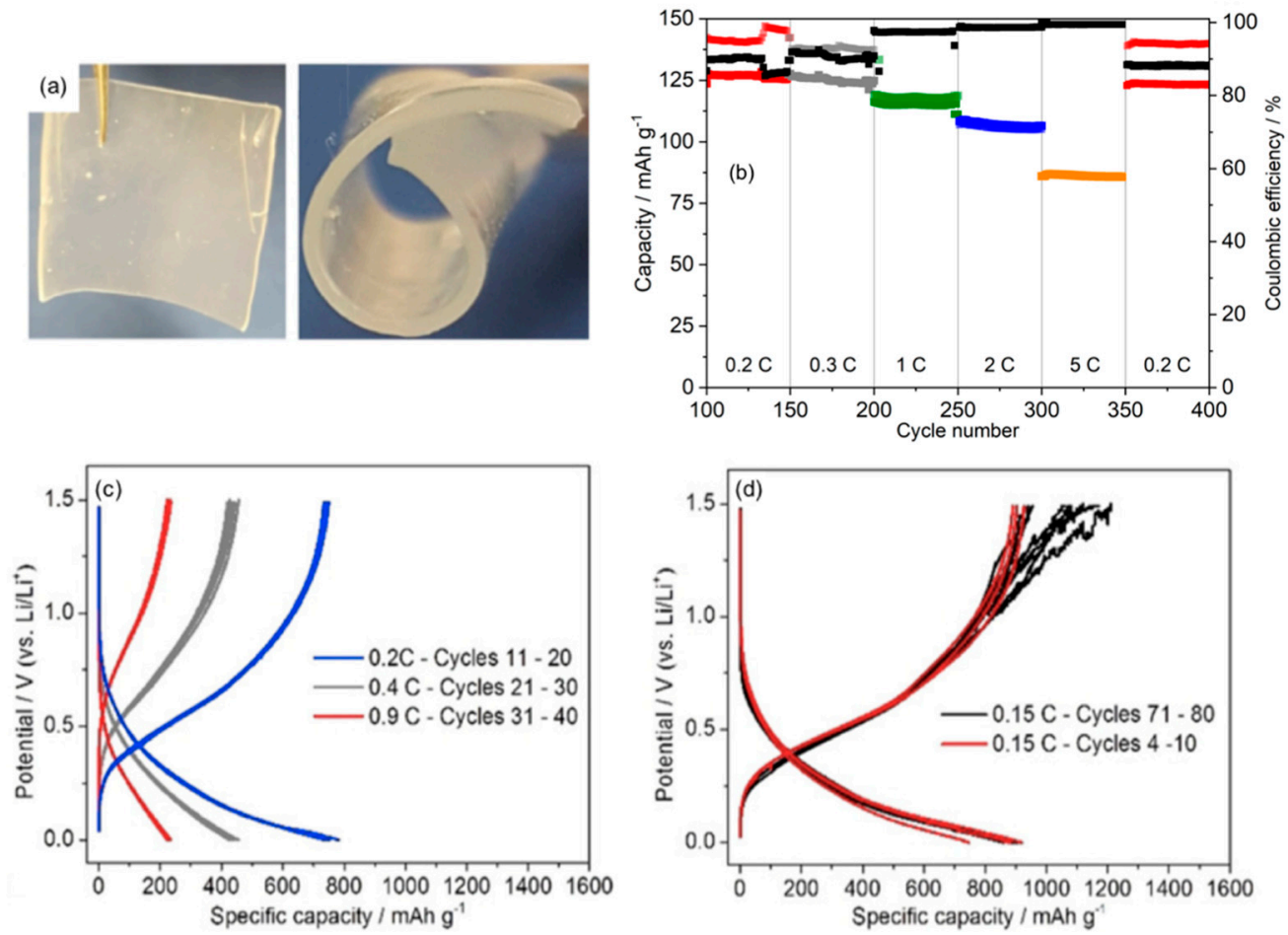

Figure 10. (a) Optical images of the $400 \mu \mathrm{m}$ thick polymer gel synthesized, (b) long-term galvanostatic cycling data for $\mathrm{V}_{2} \mathrm{O}_{5} / \mathrm{Li}$ cells at indicated C-rates and (c,d) Ge galvanostatic profiles obtained at indicated C-rates. (a,c,d) Reprinted with permission from McGrath et al. [195].

Other anode materials have been investigated using alternative polymer matrices such as the work of Balducci et al. [185] where the conventional PVDF binder was replaced with CMC. The LTO exhibited low electrode polarization during galvanostatic cycling. The electrode capacities obtained were comparable to those exhibited by LTO with PVDF binders in conventional organic electrolytes.

\subsection{Full Cell Studies}

Unlike the previous pyrrolidinium cations, both liquid and polymer gel forms of $\mathrm{C}_{4} \mathrm{mpyr}$-based electrolytes were utilized in battery prototype tests, where promising results were obtained. Various cathode and anode materials have compatibility with $\mathrm{C}_{4}$ mpyr-based ILs, and therefore comprehensive full cell tests were carried out with a variety of electrode combinations. Balducci et al. [185] investigated Li metal batteries with a polymer gel electrolyte, in addition to Li-ion batteries utilizing LTP and LTO electrodes. Prototype cells were created by stacking 12-14 single bipolar cells to achieve a theoretical cell capacity of $0.7-0.8 \mathrm{Ah}$. The electrolyte utilized with the Li-ion battery was a liquid: $\mathrm{C}_{4}$ mpyrFSI with LiTFSI salt, while the Li metal battery contained a cross-linked PEO with $\mathrm{C}_{4}$ mpyrTFSI with LiTFSI salt. In both instances 1000 cycles were obtained for each C-rate, with minimal capacity fade observed (Figure 11). The cell capacity for both the Li metal and Li-ion batteries at C/20 was close to theoretical (0.7-0.8 Ah). The Li-ion battery shows the best electrochemical performance of the two prototype batteries, however, for low to moderate C-rates, the Li metal performance was comparable to the Li-ion battery. These results show that the presence of ILs, both solid and liquid, were suitable for use in Li-based batteries. Excellent cycle life was achieved across low to high C-rates. Increased safety was exhibited during nail puncture tests as a voltage drop was observed, however a full short circuit (voltage at $0 \mathrm{~V}$ ) did not occur. Comparing this to a cell containing organic electrolyte, a full short circuit was achieved under the same conditions. Therefore, not only did the IL-based batteries have desirable electrochemical performances, but enhanced safety was also achieved, thus allowing for the realization of high-performance Li-based batteries. 

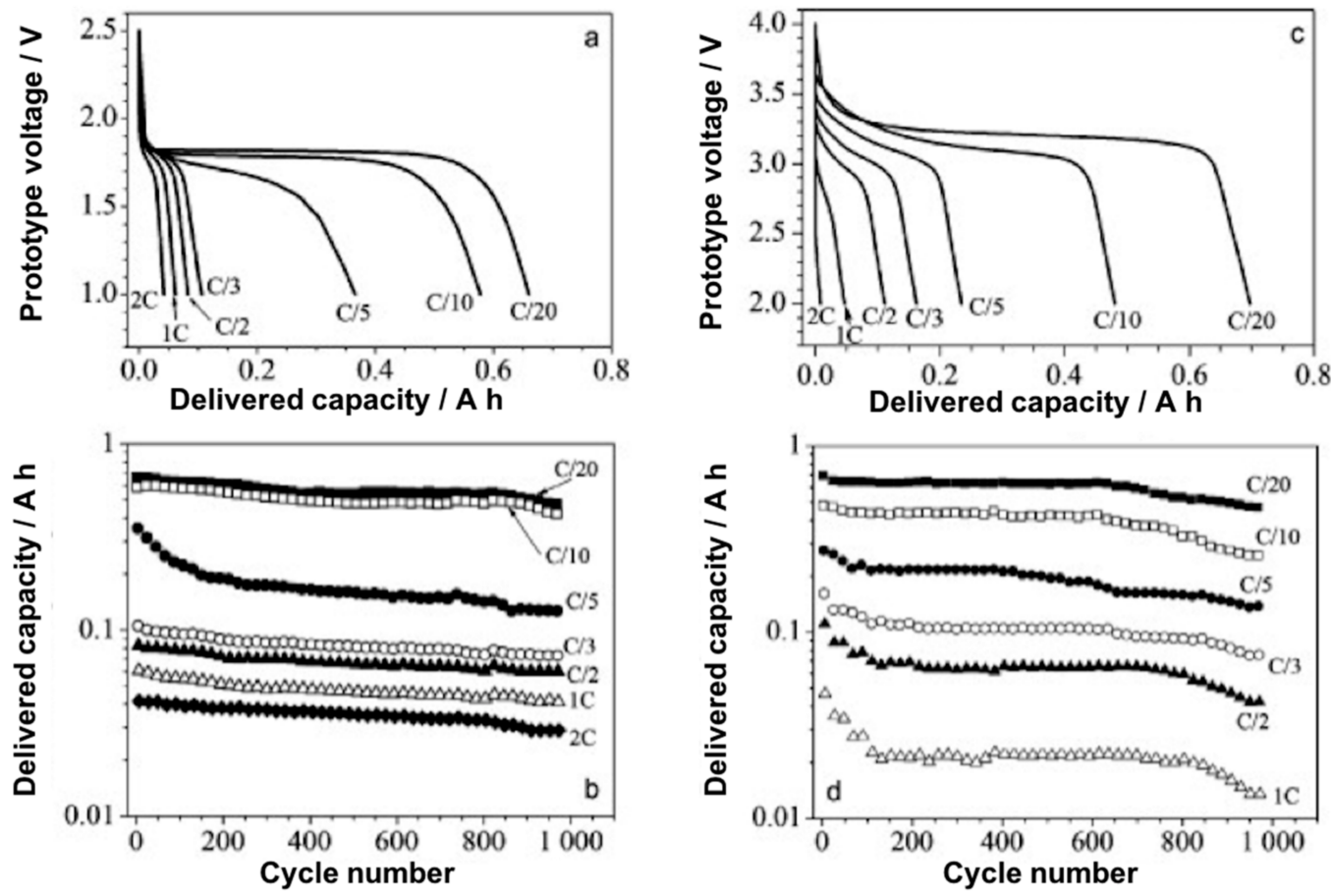

Figure 11. (a,c) First discharge voltage profiles and $(\mathbf{b}, \mathbf{d})$ capacity vs. cycle number at indicated discharge current rates of (a,b) LFP|0.9:0.1 $\mathrm{C}_{4}$ mpyrFSI:LiTFSI|LTO at $20^{\circ} \mathrm{C}$ (Li-ion battery) and (c,d) $\mathrm{LFP}\left|\mathrm{cl}-\mathrm{PEO}-\mathrm{C}_{4} \mathrm{mpyrTFSI} \mathrm{LiTFSI}\right| \mathrm{Li}$ at $40^{\circ} \mathrm{C}$ (Li metal polymer battery). Reprinted with permission from Balducci et al. [185].

Similarly, Kim et al. [196] utilized Li/LFP and LTO/LFP cells with PEO-LiTFSI-C $_{4}$ mpyrFSI, and LiTFSI- $\mathrm{C}_{4}$ mpyrFSI electrolyte, respectively. Their results reflected those obtained by Balducci et al. [185]. Full cells incorporating group IV elements with promising long-term results have been reported in the literature. Elia et al. [39] reported more than 2000 cycles with coulombic efficiency close to $100 \%$ for a Sn-C/LFP cell. From the study, it is evident that the $\mathrm{C}_{4}$ mpyrFSI-based IL allows for good high rate capabilities, as the cell capacity was $80 \mathrm{mAh} \mathrm{g}^{-1}$ at a current density of $500 \mathrm{~mA} \mathrm{~g}^{-1}$. This was maintained over 2000 cycles, with a capacity retention of $98 \%$ after cycling. The exceptional cycling is due in part to the formation of an SEI layer after 10 cycles, in addition to low interfacial resistances as verified by EIS. An analysis of the SEI layer components identified $\mathrm{SO}_{2}$ and $\mathrm{LiO}$ at the anode/electrolyte interface, while other components were identified as adherent compounds such as $\mathrm{LiF}, \mathrm{LiO}, \mathrm{LiOH}$ and $\mathrm{Li}_{2} \mathrm{SO}_{4}$. This SEI layer differs to those typically seen in TFSI-based electrolytes as $\mathrm{Li}_{2} \mathrm{CO}_{3}, \mathrm{Li}_{2} \mathrm{O}, \mathrm{Li}_{2} \mathrm{~S}$, $\mathrm{LiF}$ and $\mathrm{LiOH} / \mathrm{Li}_{2} \mathrm{O}_{2}$ are typically observed [197]. This difference in SEI layer components allows for an improved electrochemical performance, and thus allows long-term cycling with minimal capacity fade, or cell failure.

\subsection{Electrodeposition Medium}

The above results highlight that Li-ion batteries can be realized with either liquid or polymer gel electrolytes on the $\mathrm{cm}^{2}$ scale. However, in order to realize battery miniaturization $\left(\mathrm{mm}^{2}\right.$ scale) nanostructured materials are required in order to obtain high power over a small footprint, which will enable miniaturized IoT sensors. $\mathrm{C}_{4}$ mpyr-based ILs were used to realize nanostructured materials and were utilized as the electrodeposition media for group IV elements: Sn, Ge and Si. Sano et al. [198] electrodeposited $\mathrm{Sn}$ onto glassy carbon electrodes using $\mathrm{C}_{4}$ mpyrTFSI with $0.5 \mathrm{MC}_{4} \mathrm{mpyr} \mathrm{Cl}$ and $10 \mathrm{mM}$ $\mathrm{SnCl}_{2}$. Potentiostatic cathodic reduction at $-2.0 \mathrm{~V}$ resulted in tubular and granular $\mathrm{Sn}$ deposits. Similarly, electrodeposition of Ge has been achieved from a variety of $\mathrm{C}_{4}$ mpyr-based ILs [185]. Wu et al. [199] deposited Ge from 1-butyl-1-methylpyrrolidinium dicyanamide $\left(\mathrm{C}_{4} \mathrm{mpyrDCA}\right)$ using [GeCl4(BuIm) $)_{2}$ ] (BuIm $=N$-butylimidazole) as a Ge source to create thin films. Ge deposition is also feasible at high 
temperatures $\left(180^{\circ} \mathrm{C}\right)$ to produce films [200]. Lahiri et al. [201] electrodeposited free-standing Ge nanotubes and core-shell structures through electrodeposition from $\mathrm{C}_{4}$ mpyr-based ILs as shown in Figure 12.
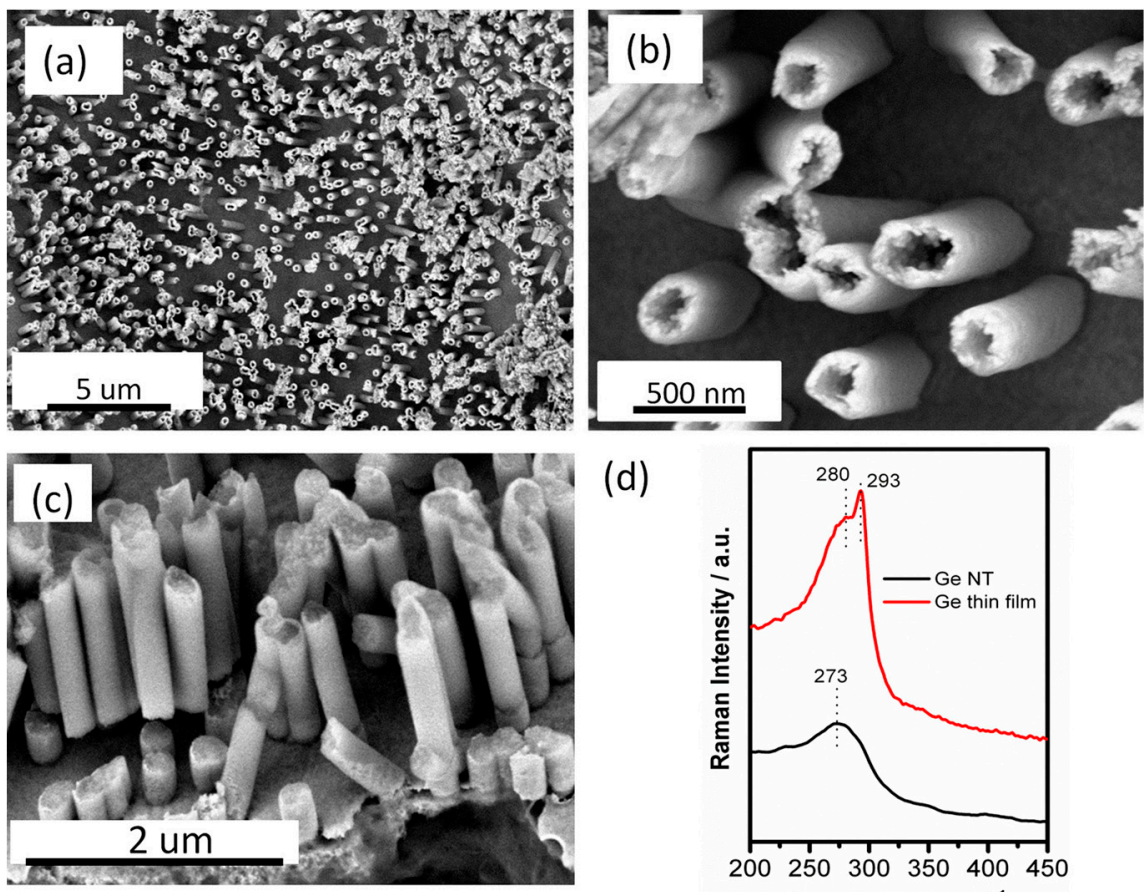

(d)

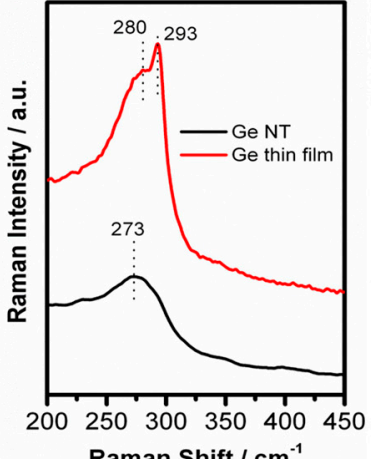

Figure 12. (a): Low magnification image of free-standing Ge nanotubes after removal of the template.

(b) Higher magnification image of the Ge nanotubes. (c) Cross sectional view of the Ge nanotubes.

(d) Raman spectra of electrodeposited Ge thin films and nanotubes obtained by exposing the sample to $5 \mathrm{~mW}, 532 \mathrm{~nm}$ laser for $10 \mathrm{~s}$. Reprinted with permission from Lahiri et al. [201].

Nanowire synthesis (NW) of both $\mathrm{Ge}$ and $\mathrm{Si}$ has been reported using $\mathrm{GeCl}_{4}$ and $\mathrm{SiCl}_{4}$ as the Ge and Si sources, respectively. Both Al-Salman et al. [202] and Martineau et al. [203] deposited amorphous Si-NW and Ge-NW with homogenous compositions. The capability to electrodeposit the anode material directly from ILs allows for greater electrode wettability, and therefore, there is an opportunity to explore further the range of high energy density materials that can be deposited from $\mathrm{C}_{4}$ mpyr-based ILs. Link et al. [204] recently investigated the initial stages of Si electrodeposition from $\mathrm{C}_{4}$ mpyrTFSI electrolytes. Their analysis suggests an instantaneous behavior of the nucleation process, showing a tendency for progressive character with decreasing the applied overpotential.

To summarize, $\mathrm{C}_{4}$ mpyr-based ILs are versatile electrolytes in which both their liquid and polymer gel options yield promising results when coupled with a variety of cathode (LCO, NCM and LTP) and anode materials (graphite, LTO, Ge, Si and Li metal) in both half-and full-cell tests. Various full cell investigations have shown the applicability of $\mathrm{C}_{4}$ mpyr-based ILs in both liquid and polymer form, which show that IL-based full cells are potential alternatives to conventional solid-state electrolytes. In addition, their ability to act as electrodeposition media can pave the way for nanostructured materials with enhanced electrode wettability.

\section{Ether Functionalized Pyrrolidinium-Based ILs}

\subsection{Liquid Electrolyte}

As with other cation types such as ammonium [37,39-46,205-207], research into ether functionalized ionic liquids are being investigated for pyrrolidinium-based ILs. Various ether functionalized pyrrolidinium ILs have been synthesized and characterized $[148,149,208]$. LFP cathodes 
are commonly analyzed with ether functionalized ILs as described in the previous sections and it is the cathode material of choice for the electrochemical characterization of ether functionalized pyrrolidinium-based ILs. Zhang et al. [209] designed an ether functionalized IL, 1-(2-ethoxyethyl)-1methylpyrrolidinium bis(trifluoromethylsulfonyl) imide (PYR $\left.\mathrm{P}_{12 \mathrm{o} 2)} \mathrm{TFSI}\right)$ in order to investigate lower viscosity, facilitate the formation of passivation layers and to enhance electrochemical stability. This IL was analyzed with LiTFSI salt, and as a cosolvent with DMC and LiTFSI salt. It was determined that the viscosity of the IL with ether functionalization was lower than for $\mathrm{C}_{4}$ mpyrTFSI with LiTFSI. Comparing the performance with a DMC electrolyte, the ether functionalized IL electrolyte matched the electrode capacity obtained by the DMC-containing electrolyte at $60^{\circ} \mathrm{C}$, which indicates that no organic components are required for high temperature applications. Superior cycling stability and rate performance of ether functionalized ILs was exhibited when compared to the non-functionalized counterparts as capacities of $100 \mathrm{mAh} \mathrm{g}^{-1}$ and $20 \mathrm{mAh} \mathrm{g}^{-1}$, respectively, were obtained at $1 \mathrm{C}$ (Figure 13).

(a)

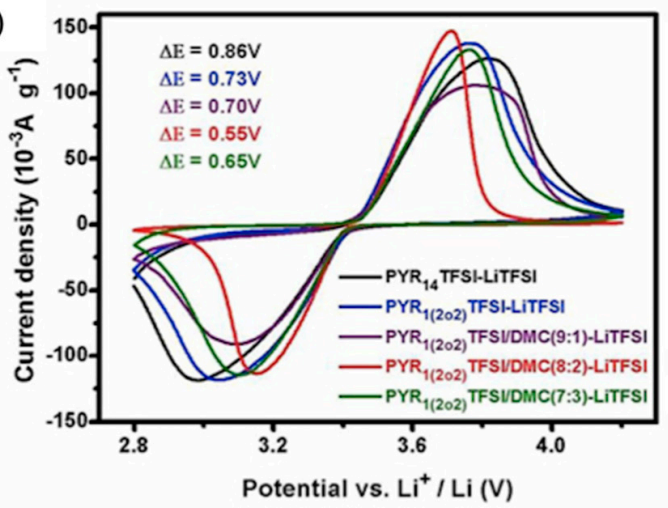

(c)

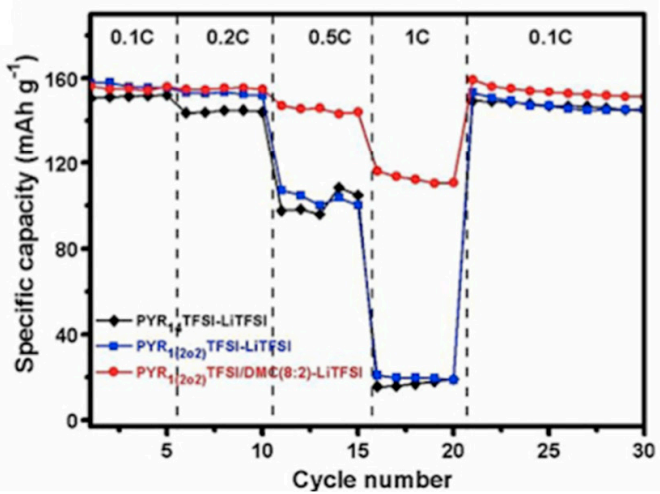

(b)

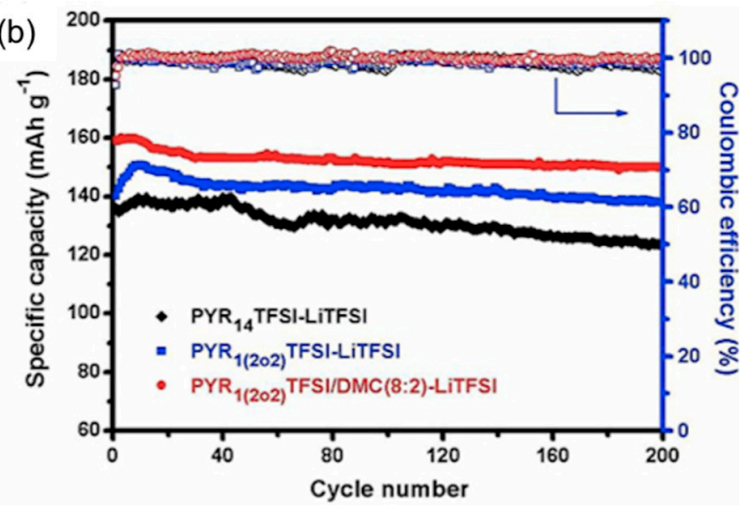

(d)

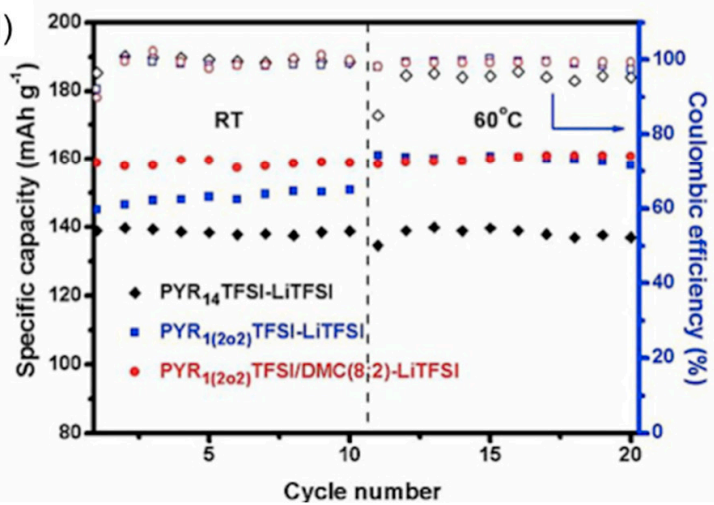

Figure 13. $(\mathbf{a}-\mathbf{c})$ Performance of various electrolytes at room temperature with LFP/Li: (a) CV curves, (b) cycling performance at $0.2 \mathrm{C},(\mathbf{c})$ rate performance at indicated C-rates and (d) cycling performance of RT and high temperature $\left(60^{\circ} \mathrm{C}\right)$. Reprinted with permission from Zhang et al. [209].

Dual ether functionalized pyrrolidinium-based ILs have been reported by Fang et al. [210]. The electrode capacities for those functionalized pyrrolidinium-based ILs are lower than the single functionalized ILs (130-140 $\mathrm{mAh} \mathrm{g}^{-1}$ vs. $150 \mathrm{mAh} \mathrm{g}^{-1}$ ), which shows that over-functionalization of the cations does not yield significant improvements in their electrochemical capabilities. Their physicochemical properties are significantly impacted as they offer lower viscosities, particularly $\mathrm{P}(2 \mathrm{o} 1)(2 \mathrm{o} 2)-\mathrm{TFSI}$, than their single- and non-functionalized counterparts (53 $\mathrm{cP}$ [210] versus $>100 \mathrm{cP}$ at $25^{\circ} \mathrm{C}$ [211]). These viscosities would allow for higher Li mobility, however, fine-tuning of the chemical structure could further improve their electrochemical abilities. These novel electrolytes show that adjustments to the chemical structure can greatly impact on its properties. This allows for further advancements in electrolyte materials and could potentially pave the way towards high powered 
batteries. Perhaps, IL electrolytes could achieve viscosities, and electrochemical performances similar to conventional organic electrolytes if the correct functionalized groups can be identified.

\subsection{Polymer Gel Analogue}

Polymer gel analogues have been synthesized by Ferrari et al. [212] whereby PVDF-HFP/silica composite membranes absorbed a solution of LiTFSI with $N$-ethyl (methylether)- $N$-methylpyrrolidinium trifluoromethanesulfonimide (PYRA ${ }_{1(201)}$ TFSI). The composite gel electrolyte yielded promising capacity retention and reversibility with LFP cathode materials with an average coulombic efficiency of $99 \%$. The specific capacity obtained for the gel composite was higher than for the liquid analogue over the long-term, yielding a capacity of $124 \mathrm{mAh} \mathrm{g}^{-1}$ after 174 cycles, while the liquid analogue only $89 \mathrm{mAh} \mathrm{g}^{-1}$ was achieved after 14 cycles. The compatibility of the PYRA $\mathrm{A}_{1(2 \mathrm{ol})}$-based gel composite electrolyte with LFP, and lower initial capacities can result in better long-term cycling as the gel composite initially had a lower capacity than its liquid counterpart $\left(139 \mathrm{mAh} \mathrm{g}^{-1}\right.$ vs. $\left.156 \mathrm{mAh} \mathrm{g}^{-1}\right)$. Further work to identify suitable ether functionalized pyrrolidinium-based ILs is required to fully utilize their potential.

\section{Other Pyrrolidinium-Based ILs}

Some pyrrolidinium cation-based ILs that have been investigated by research groups other than the cations mentioned in the previous sections include $N$ - $n$-butyl- $N$-ethylpyrrolidinium (BEPyTFSI) investigated in the early 2000s in both its liquid and polymer gel forms [213-215], however, more recently focus has been placed on dicationic ionic liquids, which consist of an anion and a doubly charged cation as head groups linked by a variable length of alkyl or oligo ethylene glycol (OEG) chain as a rigid or flexible spacer. Mei et al. [216] synthesized a variety of dicationic-based ionic liquids and characterized their physiochemical properties. No analysis was carried out to determine their suitability for battery applications, however, they exhibited high ionic conductivities of the order $10^{-3} \mathrm{~S} \mathrm{~cm}^{-1}$, comparable to the single cation-based ILs.

Symmetrical cations are also being investigated such as diethylpyrrolidinium $\left(\mathrm{C}_{2}\right.$ epyr $)$, the structure for which was shown earlier. Al-Masri et al. [217] synthesized a quasi-solid-state electrolyte containing $90 \mathrm{~mol} \%$ LiFSI salt and $\mathrm{C}_{2}$ epyrFSI, which exhibited an ionic conductivity of $2 \times 10^{-4} \mathrm{~S} \mathrm{~cm}^{-1}$ at $30^{\circ} \mathrm{C}$. This value is an improvement on those outlined in Section 4 , with typical ionic conductivities of $10^{-6} \mathrm{~S} \mathrm{~cm}^{-1}$ obtained for $\mathrm{C}_{2}$ mpyr-based electrolytes. In addition, high $\mathrm{Li}^{+}$ transference numbers, and stable lithium plating and stripping behavior was reported, supported by a reduction in dendrite formation on the lithium surface by comparison with a liquid electrolyte. These results pave the way for the development of high salt content quasi-solid-state electrolytes utilizing symmetrical pyrrolidinium cations.

\section{Conclusions}

A comprehensive review on the progress of pyrrolidinium ILs was outlined. From the discussion, there are significant areas for improvement within the pyrrolidinium family. For instance, the lack of research into compatible cathode and anode materials with $\mathrm{C}_{2}$ mpyr-based electrolytes could be an area of interest as only NCM, LFP, LTO and Li metal have been investigated to date. Considering their ability to encapsulate the electrode particles, effectively decreasing the internal resistance of the battery, and their ability to hamper Li dendritic growth [32] $\mathrm{C}_{2}$ mpyr-based electrolytes are excellent candidates for future Li-battery technology. Similarly, further research can be carried out for $\mathrm{C}_{3} \mathrm{mpyr}$-based polymer electrolytes as analysis has been limited mostly to LFP and Li metal cells. Liquid versions of $\mathrm{C}_{3}$ mpyr-based ILs have shown compatibility with $\mathrm{Si}$ electrode materials, and creation of a polymer gel analogue with similar compatibility could pave the way for high-energy dense Li-batteries.

Recent advancements into ether-functionalization of the cations demonstrate further applicability as novel electrolytes can be identified. For instance, the duel ether-functionalized electrolytes yielded capacities of $130-140 \mathrm{mAh} \mathrm{g}^{-1}$ [210], which is similar to their single-functionalized counterparts, 
however, their viscosity is significantly lower at $53 \mathrm{cP}$ [210] versus $>100 \mathrm{cP}$ at $25^{\circ} \mathrm{C}$ [211]. They have the potential to achieve viscosities similar to organic-based electrolytes, which would make them competitive as a safe alternative, provided they match the electrochemical performance of the organic electrolytes. Another area that will allow for further development is in the synthesis of new compatible anion materials such as TFSAM. Utilization of different anions will allow for more electrolyte tunability. For example, the asymmetric TFSAM anion promotes single $\mathrm{Li}^{+}$hopping due to higher structural diffusion and is capable of inhibiting crystallization over a broader temperature range when compared to TFSI [180]. In addition, alternative anions can be utilized to synthesize ILs suitable for electrodeposition, such as $\mathrm{C}_{4}$ mpyrDCA, which has been utilized to deposit Ge thin films [199].

Currently, microbattery research with ILs has been limited. This is attributed in part to the lack of understanding of the roles the cations, anions and lithium salt play in the electrochemical and physicochemical properties of ionic liquid electrolytes. This is being addressed by various research groups, where new breakdown products such as $\mathrm{N}$-butyl- $\mathrm{N}$-methyl- $\mathrm{N}$-but-3-eneamine are being discovered [175]. $\mathrm{N}$-methyl- $\mathrm{N}$-but-3-eneamine has the potential to provide elastomeric properties to accommodate changes in the electrode volume, which could facilitate the use of group IV materials in commercial microbatteries, thus enabling their use within healthcare applications such as rechargeable implantable devices where high power is required for data transmission. Studies with nanostructured $\mathrm{V}_{2} \mathrm{O}_{5}$ (nanoribbon, nanowire and microflake) have indicated promising electrochemical performances with $\mathrm{C}_{3}$ mpyrTFSI electrolytes [160]. Coupling this with their ability to deposit electrode materials in-situ can enable nanostructured active materials for microbatteries with high electrode wettability, to deliver high power in a small footprint. Promising long-term cycling of Li metal with pyrrolidinium-based IL where no short circuiting is observed after 400 cycles in both liquid and polymer gel forms [187] further indicates the applicability of ILs for microbatteries.

Ionic liquids are promising alternative electrolyte materials to both solid-state and organic electrolytes, due to their superior electrochemical and physicochemical properties, in addition to their compatibility with a wide array of cathode and anode materials. They are extremely versatile materials as they have been utilized as interlayers, additives, cosolvents, a component in mixed IL electrolytes, the sole electrolyte and as polymer gels. Their versatility is clearly highlighted in the preceding sections, with each cation offering properties, which may be tailored for specific applications. Further investigation into their properties and capabilities will allow for improvements in the miniaturization of energy storage devices for portable or miniaturized electronic devices such as sensors for the IoT.

Funding: This publication has emanated from research supported in part by a research grant from Science Foundation Ireland (SFI) and is cofunded by the European Regional Development Fund under Grant Number 13/RC/2077 and the EU EnABLES Research Infrastructure project Powering the Internet of Things, funded by the Horizon 2020 program under grant agreement number 730957.

Conflicts of Interest: The authors declare no conflict of interest.

\section{References}

1. Statista. Internet of Things (IoT) Connected Devices Installed Base Worldwide from 2015 to 2025 (In Billions). Available online: https://www.statista.com/statistics/471264/iot-number-of-connected-devices-worldwide/ (accessed on 27 October 2020).

2. Cook-Chennault, K.A.; Thambi, N.; Sastry, A.M. Powering MEMS portable devices-A review of non-regenerative and regenerative power supply systems with special emphasis on piezoelectric energy harvesting systems. Smart Mater. Struct. 2008, 17, 043001. [CrossRef]

3. Gogotsi, Y.; Simon, P. True Performance Metrics in Electrochemical Energy Storage. Science 2011, 334, 917-918. [CrossRef] [PubMed]

4. Zhu, J.; Jiang, J.; Feng, Y.; Meng, G.; Ding, H.; Huang, X. Three-Dimensional Ni/SnOx/C Hybrid Nanostructured Arrays for Lithium-Ion Microbattery Anodes with Enhanced Areal Capacity. ACS Appl. Mater. Interfaces 2013, 5, 2634-2640. [CrossRef] [PubMed] 
5. Wang, W.; Tian, M.; Abdulagatov, A.; George, S.M.; Lee, Y.-C.; Yang, R. Three-Dimensional Ni/TiO2 Nanowire Network for High Areal Capacity Lithium Ion Microbattery Applications. Nano Lett. 2012, 12, 655-660. [CrossRef] [PubMed]

6. Barrera, P. Top Cobalt Reserves by Country. Available online: https://investingnews.com/daily/resource-investing/ battery-metals-investing/cobalt-investing/cobalt-producer-cobalt-reserves/ (accessed on 10 February 2020).

7. Economics, T. Cobalt 2010-2020 Data. Available online: https://tradingeconomics.com/commodity/cobalt (accessed on 10 February 2020).

8. Chen, R.-J.; Zhang, Y.-B.; Liu, T.; Xu, B.-Q.; Lin, Y.-H.; Nan, C.-W.; Shen, Y. Addressing the Interface Issues in All-Solid-State Bulk-Type Lithium Ion Battery via an All-Composite Approach. ACS Appl. Mater. Interfaces 2017, 9, 9654-9661. [CrossRef]

9. Hovington, P.; Lagacé, M.; Guerfi, A.; Bouchard, P.; Mauger, A.; Julien, C.M.; Armand, M.; Zaghib, K. New Lithium Metal Polymer Solid State Battery for an Ultrahigh Energy: Nano C-LiFePO $\mathrm{H}_{4}$ versus Nano $\mathrm{Li}_{1.2} \mathrm{~V}_{3} \mathrm{O}_{8}$. Nano Lett. 2015, 15, 2671-2678. [CrossRef]

10. Porcarelli, L.; Aboudzadeh, M.A.; Rubatat, L.; Nair, J.R.; Shaplov, A.S.; Gerbaldi, C.; Mecerreyes, D. Single-ion triblock copolymer electrolytes based on poly(ethylene oxide) and methacrylic sulfonamide blocks for lithium metal batteries. J. Power Sources 2017, 364, 191-199. [CrossRef]

11. Bouchet, R.; Maria, S.; Meziane, R.; Aboulaich, A.; Lienafa, L.; Bonnet, J.-P.; Phan, T.N.T.; Bertin, D.; Gigmes, D.; Devaux, D.; et al. Single-ion BAB triblock copolymers as highly efficient electrolytes for lithium-metal batteries. Nat. Mater. 2013, 12, 452-457. [CrossRef] [PubMed]

12. Yu, S.; Mertens, A.; Tempel, H.; Schierholz, R.; Kungl, H.; Eichel, R.-A. Monolithic All-Phosphate Solid-State Lithium-Ion Battery with Improved Interfacial Compatibility. ACS Appl. Mater. Interfaces 2018, 10, 22264-22277. [CrossRef] [PubMed]

13. Zhang, Q.; Peng, G.; Mwizerwa, J.P.; Wan, H.; Cai, L.; Xu, X.; Yao, X. Nickel sulfide anchored carbon nanotubes for all-solid-state lithium batteries with enhanced rate capability and cycling stability. J. Mater. Chem. A 2018, 6, 12098-12105. [CrossRef]

14. Chen, Y.; Wang, Z.; Li, X.; Yao, X.; Wang, C.; Li, Y.; Xue, W.; Yu, D.; Kim, S.Y.; Yang, F.; et al. Li metal deposition and stripping in a solid-state battery via Coble creep. Nature 2020, 578, 251-255. [CrossRef] [PubMed]

15. Hsu, S.-T.; Tran, B.T.; Subramani, R.; Nguyen, H.T.T.; Rajamani, A.; Lee, M.-Y.; Hou, S.-S.; Lee, Y.-L.; Teng, H. Free-standing polymer electrolyte for all-solid-state lithium batteries operated at room temperature. J. Power Sources 2020, 449, 227518. [CrossRef]

16. Chen, Q.; Xu, R.; He, Z.; Zhao, K.; Pan, L. Printing 3D Gel Polymer Electrolyte in Lithium-Ion Microbattery Using Stereolithography. J. Electrochem. Soc. 2017, 164, A1852-A1857. [CrossRef]

17. Matsuda, Y.; Kuwata, N.; Kawamura, J. Thin-film lithium batteries with 0.3-30 $\mu \mathrm{m}$ thick $\mathrm{LiCoO}_{2}$ films fabricated by high-rate pulsed laser deposition. Solid State Ionics 2018, 320, 38-44. [CrossRef]

18. Matsuda, Y.; Kuwata, N.; Okawa, T.; Dorai, A.; Kamishima, O.; Kawamura, J. In Situ Raman spectroscopy of $\mathrm{LixCoO}$ cathode in $\mathrm{Li} / \mathrm{Li}_{3} \mathrm{PO}_{4} / \mathrm{LiCoO}_{2}$ all-solid-state thin-film lithium battery. Solid State Ionics 2019, 335, 7-14. [CrossRef]

19. Honghe, Z.; Jianhua, Q.; Yang, Z.; Takeshi, A.; Zempachi, O. Temperature dependence of the electrochemical behavior of $\mathrm{LiCoO}_{2}$ in quaternary ammonium-based ionic liquid electrolyte. Solid State Ionics 2005, 176, 2219-2226. [CrossRef]

20. Sakaebe, H.; Matsumoto, H.; Tatsumi, K. Discharge-charge properties of $\mathrm{Li} / \mathrm{LiCoO}_{2}$ cell using room temperature ionic liquids (RTILs) based on quaternary ammonium cation-Effect of the structure. J. Power Sources 2005, 146, 693-697. [CrossRef]

21. Zheng, H.; Zhang, H.; Fu, Y.; Abe, T.; Ogumi, Z. Temperature Effects on the Electrochemical Behavior of Spinel LiMn2O4 in Quaternary Ammonium-Based Ionic Liquid Electrolyte. J. Phys. Chem. B 2005, 109, 13676-13684. [CrossRef]

22. Zheng, H.; Li, B.; Fu, Y.; Abe, T.; Ogumi, Z. Compatibility of quaternary ammonium-based ionic liquid electrolytes with electrodes in lithium ion batteries. Electrochim. Acta 2006, 52, 1556-1562. [CrossRef]

23. Wang, Z.; Cai, Y.; Dong, T.; Chen, S.; Lu, X. Triethylbutylammonium bis(trifluoromethanesulphonyl)imide ionic liquid as an effective electrolyte additive for Li-ion batteries. Ionics 2013, 19, 887-894. [CrossRef] 
24. Egashira, M.; Okada, S.; Yamaki, J.-i.; Dri, D.A.; Bonadies, F.; Scrosati, B. The preparation of quaternary ammonium-based ionic liquid containing a cyano group and its properties in a lithium battery electrolyte. J. Power Sources 2004, 138, 240-244. [CrossRef]

25. Egashira, M.; Tanaka-Nakagawa, M.; Watanabe, I.; Okada, S.; Yamaki, J.-I. Charge-discharge and high temperature reaction of $\mathrm{LiCoO}_{2}$ in ionic liquid electrolytes based on cyano-substituted quaternary ammonium cation. J. Power Sources 2006, 160, 1387-1390. [CrossRef]

26. Katayama, Y.; Yukumoto, M.; Miura, T. Electrochemical Intercalation of Lithium into Graphite in Room-Temperature Molten Salt Containing Ethylene Carbonate. Electrochem. Solid State Lett. 2003, 6, A96. [CrossRef]

27. Zheng, H.; Jiang, K.; Abe, T.; Ogumi, Z. Electrochemical intercalation of lithium into a natural graphite anode in quaternary ammonium-based ionic liquid electrolytes. Carbon 2006, 44, 203-210. [CrossRef]

28. Zheng, H.; Liu, G.; Battaglia, V. Film-Forming Properties of Propylene Carbonate in the Presence of a Quaternary Ammonium Ionic Liquid on Natural Graphite Anode. J. Phys. Chem. C 2010, 114, 6182-6189. [CrossRef]

29. Chakrapani, V.; Rusli, F.; Filler, M.A.; Kohl, P.A. Quaternary Ammonium Ionic Liquid Electrolyte for a Silicon Nanowire-Based Lithium Ion Battery. J. Phys. Chem. C 2011, 115, 22048-22053. [CrossRef]

30. Löwe, R.; Hanemann, T.; Hofmann, A. Polymerizable Ionic Liquids for Solid-State Polymer Electrolytes. Molecules 2019, 24, 324. [CrossRef]

31. Egashira, M.; Todo, H.; Yoshimoto, N.; Morita, M. Lithium ion conduction in ionic liquid-based gel polymer electrolyte. J. Power Sources 2008, 178, 729-735. [CrossRef]

32. Ogawa, H.; Mori, H. In-situ formation of poly(ionic liquid)s with ionic liquid-based plasticizer and lithium salt in electrodes for solid-state lithium batteries. Polymer 2019, 178, 121614. [CrossRef]

33. Zhang, Z.; Chen, S.; Yang, J.; Wang, J.; Yao, L.; Yao, X.; Cui, P.; Xu, X. Interface Re-Engineering of $\mathrm{Li}_{10} \mathrm{GeP}_{2} \mathrm{~S}_{12}$ Electrolyte and Lithium anode for All-Solid-State Lithium Batteries with Ultralong Cycle Life. ACS Appl. Mater. Interfaces 2018, 10, 2556-2565. [CrossRef]

34. Xie, D.; Chen, S.; Zhang, Z.; Ren, J.; Yao, L.; Wu, L.; Yao, X.; Xu, X. High ion conductive Sb2O5-doped $\beta$-Li3PS4 with excellent stability against Li for all-solid-state lithium batteries. J. Power Sources 2018, 389, 140-147. [CrossRef]

35. Teranishi, T.; Inohara, M.; Kano, J.; Hayashi, H.; Kishimoto, A.; Yoda, K.; Motobayashi, H.; Tasaki, Y. Synthesis of nano-crystalline $\mathrm{LiNbO}_{3}$-decorated $\mathrm{LiCoO}_{2}$ and resulting high-rate capabilities. Solid State Ionics 2018, 314, 57-60. [CrossRef]

36. Seki, S.; Kobayashi, Y.; Miyashiro, H.; Ohno, Y.; Usami, A.; Mita, Y.; Watanabe, M.; Terada, N. Highly reversible lithium metal secondary battery using a room temperature ionic liquid/lithium salt mixture and a surface-coated cathode active material. Chem. Commun. 2006, 544-545. [CrossRef] [PubMed]

37. Gao, X.; Wu, F.; Mariani, A.; Passerini, S. Concentrated Ionic-Liquid-Based Electrolytes for High-Voltage Lithium Batteries with Improved Performance at Room Temperature. Chem. Sus. Chem. 2019, 12, 4185-4193. [CrossRef]

38. Elia, G.A.; Ulissi, U.; Mueller, F.; Reiter, J.; Tsiouvaras, N.; Sun, Y.-K.; Scrosati, B.; Passerini, S.; Hassoun, J. A Long-Life Lithium Ion Battery with Enhanced Electrode/Electrolyte Interface by Using an Ionic Liquid Solution. Chem. A Eur. J. 2016, 22, 6808-6814. [CrossRef]

39. Elia, G.A.; Ulissi, U.; Jeong, S.; Passerini, S.; Hassoun, J. Exceptional long-life performance of lithium-ion batteries using ionic liquid-based electrolytes. Energy Environ. Sci. 2016, 9, 3210-3220. [CrossRef]

40. Li, M.; Yang, B.; Wang, L.; Zhang, Y.; Zhang, Z.; Fang, S.; Zhang, Z. New polymerized ionic liquid (PIL) gel electrolyte membranes based on tetraalkylammonium cations for lithium ion batteries. J. Membr. Sci. 2013, 447, 222-227. [CrossRef]

41. Li, M.; Wang, L.; Yang, B.; Du, T.; Zhang, Y. Facile preparation of polymer electrolytes based on the polymerized ionic liquid poly((4-vinylbenzyl)trimethylammonium bis(trifluoromethanesulfonylimide)) for lithium secondary batteries. Electrochim. Acta 2014, 123, 296-302. [CrossRef]

42. Zhou, N.; Wang, Y.; Zhou, Y.; Shen, J.; Zhou, Y.; Yang, Y. Star-shaped multi-arm polymeric ionic liquid based on tetraalkylammonium cation as high performance gel electrolyte for lithium metal batteries. Electrochim. Acta 2019, 301, 284-293. [CrossRef]

43. Sato, T.; Marukane, S.; Narutomi, T.; Akao, T. High rate performance of a lithium polymer battery using a novel ionic liquid polymer composite. J. Power Sources 2007, 164, 390-396. [CrossRef] 
44. Fang, S.; Qu, L.; Luo, D.; Shen, S.; Yang, L.; Hirano, S.-i. Novel mixtures of ether-functionalized ionic liquids and non-flammable methylperfluorobutylether as safe electrolytes for lithium metal batteries. RSC Adv. 2015, 5, 33897-33904. [CrossRef]

45. Han, H.-B.; Liu, K.; Feng, S.-W.; Zhou, S.-S.; Feng, W.-F.; Nie, J.; Li, H.; Huang, X.-J.; Matsumoto, H.; Armand, M.; et al. Ionic liquid electrolytes based on multi-methoxyethyl substituted ammoniums and perfluorinated sulfonimides: Preparation, characterization, and properties. Electrochim. Acta 2010, 55, 7134-7144. [CrossRef]

46. Fang, S.; Jin, Y.; Yang, L.; Hirano, S.-i.; Tachibana, K.; Katayama, S. Functionalized ionic liquids based on quaternary ammonium cations with three or four ether groups as new electrolytes for lithium battery. Electrochim. Acta 2011, 56, 4663-4671. [CrossRef]

47. Gupta, H.; Na, S.; Balo, L.; Singh, V.K.; Singh, S.K.; Tripathi, A.K.; Verma, Y.L.; Singh, R.K. Effect of temperature on electrochemical performance of ionic liquid based polymer electrolyte with $\mathrm{Li} / \mathrm{LiFePO}_{4}$ electrodes. Solid State Ionics 2017, 309, 192-199. [CrossRef]

48. Cheng, H.; Zhu, C.; Huang, B.; Lu, M.; Yang, Y. Synthesis and electrochemical characterization of PEO-based polymer electrolytes with room temperature ionic liquids. Electrochim. Acta 2007, 52, 5789-5794. [CrossRef]

49. Yang, P.; Liu, L.; Li, L.; Hou, J.; Xu, Y.; Ren, X.; An, M.; Li, N. Gel polymer electrolyte based on polyvinylidenefluoride-co-hexafluoropropylene and ionic liquid for lithium ion battery. Electrochim. Acta 2014, 115, 454-460. [CrossRef]

50. Park, J.; Lee, C.; Kwon, K.; Kim, H. Electrodeposition of Silicon from 1-butyl-3-methyl-pyridinium bis(trifluromethylsulfonyl) imide ionic liquid. Int. J. Electrochem. Sci. 2013, 8, 4206-4214.

51. Belhocine, T.; Forsyth, S.A.; Gunaratne, H.Q.N.; Nieuwenhuyzen, M.; Nockemann, P.; Puga, A.V.; Seddon, K.R.; Srinivasan, G.; Whiston, K. 3-Methylpiperidinium ionic liquids. Phys. Chem. Chem. Phys 2015, 17, 10398-10416. [CrossRef]

52. Fang, L.; Hu, Y.; Qi, J.; Chen, Y.; Zhang, H.; Huang, H. The physical and electrochemical properties of the ionic liquids based on N-ethylpiperidinium cations and TFSI anion. Electrochim. Acta 2014, 133, 440-445. [CrossRef]

53. Kim, K.; Cho, Y.H.; Shin, H.C. 1-Ethyl-1-methyl piperidinium bis(trifluoromethanesulfonyl)imide as a co-solvent in Li-ion batteries. J. Power Sources 2013, 225, 113-118. [CrossRef]

54. Berger, C.A.; Ceblin, M.U.; Jacob, T. Lithium Deposition from a Piperidinium-based Ionic Liquid: Rapping Dendrites on the Knuckles. Chem. Electro. Chem. 2017, 4, 261-265. [CrossRef]

55. Sakaebe, H.; Matsumoto, H. N-Methyl-N-propylpiperidinium bis(trifluoromethanesulfonyl)imide (PP13-TFSI)—Novel electrolyte base for Li battery. Electrochem. Commun. 2003, 5, 594-598. [CrossRef]

56. Xu, J.; Yang, J.; NuLi, Y.; Wang, J.; Zhang, Z. Additive-containing ionic liquid electrolytes for secondary lithium battery. J. Power Sources 2006, 160, 621-626. [CrossRef]

57. Liu, Q.; Su, X.; Lei, D.; Qin, Y.; Wen, J.; Guo, F.; Wu, Y.; Rong, Y.; Kou, R.; Xiao, X.; et al. Approaching the capacity limit of lithium cobalt oxide in lithium ion batteries via lanthanum and aluminium doping. Nat. Energy 2018, 3. [CrossRef]

58. Sun, X.G.; Dai, S. Electrochemical investigations of ionic liquids with vinylene carbonate for applications in rechargeable lithium ion batteries. Electrochim. Acta 2010, 55, 4618-4626. [CrossRef]

59. Reiter, J.; Nádherná, M.; Dominko, R. Graphite and LiCo1/3Mn1/3Ni1/3O2 electrodes with piperidinium ionic liquid and lithium bis(fluorosulfonyl)imide for Li-ion batteries. J. Power Sources 2012, 205, 402-407. [CrossRef]

60. Borgel, V.; Markevich, E.; Aurbach, D.; Semrau, G.; Schmidt, M. On the application of ionic liquids for rechargeable Li batteries: High voltage systems. J. Power Sources 2009, 189, 331-336. [CrossRef]

61. Solvionic. 1-Butyl-1-Methylpyrrolidinium Bis(Trifluoromethanesulfonyl)imide 99.9\%. Available online: https: //en.solvionic.com/products/1-butyl-1-methylpyrrolidinium-bistrifluoromethanesulfonylimide-99.9 (accessed on 27 October 2020).

62. Solvionic. N-propyl-N-Methylpiperidinium Bis(trifluoromethanesulfonyl)imide 99.9\%. Available online: https:/en.solvionic.com/products/n-propyl-n-methylpiperidinium-bistrifluoromethanesulfonylimide-99.9 (accessed on 27 October 2020).

63. Liang, F.; Yu, J.; Wang, D.; Dong, L.; Ma, C.; Chen, J.; Yang, B.; Zhu, C.; Gao, Y.; Li, C. Exceptional cycling performance of a graphite/ $\mathrm{Li}_{1.1} \mathrm{Ni}_{0.25} \mathrm{Mn}_{0.65} \mathrm{O}_{2}$ battery at high voltage with ionic liquid-based electrolyte. Electrochim. Acta 2019, 307, 83-91. [CrossRef] 
64. Rangasamy, V.S.; Thayumanasundaram, S.; Locquet, J.P. Solid polymer electrolytes with poly(vinyl alcohol) and piperidinium based ionic liquid for Li-ion batteries. Solid State Ion. 2019, 333, 76-82. [CrossRef]

65. Gauthier, C.; Plesse, C.; Vidal, F.; Pelletier, J.-M.; Chevrot, C.; Teyssié, D. Polybutadiene/poly(ethylene oxide) based IPNs, Part II: Mechanical modelling and $\mathrm{LiClO}_{4}$ loading as tools for IPN morphology investigation. Polymer 2007, 48, 7476-7483. [CrossRef]

66. Rosol, Z.P.; German, N.J.; Gross, S.M. Solubility, ionic conductivity and viscosity of lithium salts in room temperature ionic liquids. Green Chem. 2009, 11, 1453-1457. [CrossRef]

67. Selvasekarapandian, S.; Baskaran, R.; Kamishima, O.; Kawamura, J.; Hattori, T. Laser Raman and FTIR studies on $\mathrm{Li}+$ interaction in PVAc-LiClO4 polymer electrolytes. Spectrochim. Acta Part A 2006, 65, 1234-1240. [CrossRef] [PubMed]

68. Thayumanasundaram, S.; Rangasamy, V.S.; Seo, J.W.; Locquet, J.-P. Lithium Polymer Electrolytes Based on Sulfonated Poly(ether ether ketone) for Lithium Polymer Batteries. Eur. J. Inorg. Chem. 2015, 2015, 5395-5404. [CrossRef]

69. Libo, L.; Jiesi, L.; Shuo, Y.; Shaowen, G.; Peixia, Y. Gel polymer electrolytes containing ionic liquids prepared by radical polymerization. Colloids Surf. A 2014, 459, 136-141. [CrossRef]

70. Pan, X.; Liu, T.; Kautz, D.J.; Mu, L.; Tian, C.; Long, T.E.; Yang, P.; Lin, F. High-performance N-methyl$\mathrm{N}$-propylpiperidinium bis(trifluoromethanesulfonyl)imide/poly(vinylidene fluoride-hexafluoropropylene) gel polymer electrolytes for lithium metal batteries. J. Power Sources 2018, 403, 127-136. [CrossRef]

71. Gao, K.; Li, S.-D. $\mathrm{Li}_{4} \mathrm{Ti}_{5} \mathrm{O}_{12}$ coated graphite anodes with piperidinium-based hybrid electrolytes for lithium ion batteries. J. Power Sources 2014, 270, 304-311. [CrossRef]

72. Korf, K.S.; Lu, Y.; Kambe, Y.; Archer, L.A. Piperidinium tethered nanoparticle-hybrid electrolyte for lithium metal batteries. J. Mater. Chem. A 2014, 2, 11866-11873. [CrossRef]

73. Rodrigues, M.T.F.; Kalaga, K.; Gullapalli, H.; Babu, G.; Reddy, A.L.M.; Ajayan, P.M. Hexagonal Boron Nitride-Based Electrolyte Composite for Li-Ion Battery Operation from Room Temperature to $150{ }^{\circ} \mathrm{C}$. Adv. Energy Mater. 2016, 6. [CrossRef]

74. Lu, Y.; Das, S.K.; Moganty, S.S.; Archer, L.A. Ionic Liquid-Nanoparticle Hybrid Electrolytes and their Application in Secondary Lithium-Metal Batteries. Adv. Mater. 2012, 24, 4430-4435. [CrossRef]

75. Lu, Y.; Korf, K.; Kambe, Y.; Tu, Z.; Archer, L.A. Ionic-Liquid-Nanoparticle Hybrid Electrolytes: Applications in Lithium Metal Batteries. Angew. Chem. Int. Ed. 2014, 53, 488-492. [CrossRef]

76. Lu, Y.; Moganty, S.S.; Schaefer, J.L.; Archer, L.A. Ionic liquid-nanoparticle hybrid electrolytes. J. Mater. Chem. 2012, 22, 4066-4072. [CrossRef]

77. Ababtain, K.; Babu, G.; Lin, X.; Rodrigues, M.-T.F.; Gullapalli, H.; Ajayan, P.M.; Grinstaff, M.W.; Arava, L.M.R. Ionic Liquid-Organic Carbonate Electrolyte Blends To Stabilize Silicon Electrodes for Extending Lithium Ion Battery Operability to $100{ }^{\circ} \mathrm{C}$. ACS Appl. Mater. Interfaces 2016, 8, 15242-15249. [CrossRef] [PubMed]

78. Tong, J.; Wu, S.; von Solms, N.; Liang, X.; Huo, F.; Zhou, Q.; He, H.; Zhang, S. The Effect of Concentration of Lithium Salt on the Structural and Transport Properties of Ionic Liquid-Based Electrolytes. Front. Chem. 2020, 7. [CrossRef] [PubMed]

79. Kamiyama, Y.; Shibata, M.; Kanzaki, R.; Fujii, K. Lithium-ion coordination-induced conformational change of PEG chains in ionic-liquid-based electrolytes. Phys. Chem. Chem. Phys 2020, 22, 5561-5567. [CrossRef] [PubMed]

80. Sayah, S.; Ghamouss, F.; Santos-Pena, J.; Tran-Van, F.; Lemordant, D. The Intriguing Properties of 1-Ethyl-3-methylimidazolium bis(fluorosulfonyl)imide Ionic Liquid. J. Solut. Chem. 2019, 48, 992-1008. [CrossRef]

81. Yambou, E.P.; Gorska, B.; Béguin, F. Binary mixtures of ionic liquids based on EMIm cation and fluorinated anions: Physico-chemical characterization in view of their application as low-temperature electrolytes. J. Mol. Liq. 2020, 298, 111959. [CrossRef]

82. Seki, S.; Kobayashi, Y.; Miyashiro, H.; Ohno, Y.; Usami, A.; Mita, Y.; Kihira, N.; Watanabe, M.; Terada, N. Lithium Secondary Batteries Using Modified-Imidazolium Room-Temperature Ionic Liquid. J. Phys. Chem. B 2006, 110, 10228-10230. [CrossRef]

83. Yamagata, M.; Tanaka, K.; Tsuruda, Y.; Sone, Y.; Fukuda, S.; Nakasuka, S.; Kono, M.; Ishikawa, M. The First Lithium-ion Battery with Ionic Liquid Electrolyte Demonstrated in Extreme Environment of Space. Electrochemistry 2015, 83, 918-924. [CrossRef] 
84. Balo, L.; Gupta, H.; Singh, S.K.; Singh, V.K.; Tripathi, A.K.; Srivastava, N.; Tiwari, R.K.; Mishra, R.; Meghnani, D.; Singh, R.K. Development of gel polymer electrolyte based on LiTFSI and EMIMFSI for application in rechargeable lithium metal battery with GO-LFP and NCA cathodes. J. Solid State Electrochem. 2019, 23, 2507-2518. [CrossRef]

85. Egashira, M.; Kanetomo, A.; Yoshimoto, N.; Morita, M. Charge-discharge rate of spinel lithium manganese oxide and olivine lithium iron phosphate in ionic liquid-based electrolytes. J. Power Sources 2011, 196, 6419-6424. [CrossRef]

86. Le, L.T.M.; Vo, T.D.; Ngo, K.H.P.; Okada, S.; Alloin, F.; Garg, A.; Le, P.M.L. Mixing ionic liquids and ethylene carbonate as safe electrolytes for lithium-ion batteries. J. Mol. Liq. 2018, 271, 769-777. [CrossRef]

87. Karuppasamy, K.; Vikraman, D.; Hwang, I.-T.; Kim, H.-J.; Nichelson, A.; Bose, R.; Kim, H.-S. Nonaqueous liquid electrolytes based on novel 1-ethyl-3-methylimidazolium bis (nonafluorobutane-1-sulfonyl imidate) ionic liquid for energy storage devices. J. Mater. Res. Technol. 2020, 9, 1251-1260. [CrossRef]

88. Singh, S.K.; Na, S.; Balo, L.; Gupta, H.; Singh, V.K.; Tripathi, A.K.; Verma, Y.L.; Singh, R.K. Improved electrochemical performance of EMIMFSI ionic liquid based gel polymer electrolyte with temperature for rechargeable lithium battery. Energy 2018, 150, 890-900. [CrossRef]

89. Yang, P.; Cui, W.; Li, L.; Liu, L.; An, M. Characterization and properties of ternary P(VdF-HFP)-LiTFSI-EMITFSI ionic liquid polymer electrolytes. Solid State Sci. 2012, 14, 598-606. [CrossRef]

90. Tseng, Y.-C.; Wu, Y.; Tsao, C.-H.; Teng, H.; Hou, S.-S.; Jan, J.-S. Polymer electrolytes based on Poly(VdF-co-HFP)/ionic liquid/carbonate membranes for high-performance lithium-ion batteries. Polymer 2019, 173, 110-118. [CrossRef]

91. Liao, Y.; Li, G.; Xu, N.; Chen, T.; Wang, X.; Li, W. Synergistic effect of electrolyte additives on the improvement in interfacial stability between ionic liquid based gel electrolyte and $\mathrm{LiFePO}_{4}$ cathode. Solid State Ion. 2019, 329, 31-39. [CrossRef]

92. Safa, M.; Chamaani, A.; Chawla, N.; El-Zahab, B. Polymeric Ionic Liquid Gel Electrolyte for Room Temperature Lithium Battery Applications. Electrochim. Acta 2016, 213, 587-593. [CrossRef]

93. Safa, M.; Adelowo, E.; Chamaani, A.; Chawla, N.; Baboukani, A.R.; Herndon, M.; Wang, C.; El-Zahab, B. Poly(Ionic Liquid)-Based Composite Gel Electrolyte for Lithium Batteries. Chem. Electro. Chem. 2019, 6, 3319-3326. [CrossRef]

94. Ui, K.; Minami, T.; Ishikawa, K.; Idemoto, Y.; Koura, N. Development of non-flammable lithium secondary battery with ambient-temperature molten salt electrolyte: Performance of binder-free carbon-negative electrode. J. Power Sources 2005, 146, 698-702. [CrossRef]

95. Yamagata, M.; Nishigaki, N.; Nishishita, S.; Matsui, Y.; Sugimoto, T.; Kikuta, M.; Higashizaki, T.; Kono, M.; Ishikawa, M. Charge-discharge behavior of graphite negative electrodes in bis(fluorosulfonyl)imide-based ionic liquid and structural aspects of their electrode/electrolyte interfaces. Electrochim. Acta 2013, 110, 181-190. [CrossRef]

96. Matsui, Y.; Yamagata, M.; Murakami, S.; Saito, Y.; Higashizaki, T.; Ishiko, E.; Kono, M.; Ishikawa, M. Design of an electrolyte composition for stable and rapid charging-discharging of a graphite negative electrode in a bis(fluorosulfonyl)imide-based ionic liquid. J. Power Sources 2015, 279, 766-773. [CrossRef]

97. Yamaguchi, K.; Domi, Y.; Usui, H.; Shimizu, M.; Morishita, S.; Yodoya, S.; Sakata, T.; Sakaguchi, H. Effect of Film-Forming Additive in Ionic Liquid Electrolyte on Electrochemical Performance of Si Negative-Electrode for LIBs. J. Electrochem. Soc. 2019, 166, A268-A276. [CrossRef]

98. Chapman Varela, J.; Sankar, K.; Hino, A.; Lin, X.; Chang, W.-S.; Coker, D.; Grinstaff, M. Piperidinium ionic liquids as electrolyte solvents for sustained high temperature supercapacitor operation. Chem. Commun. 2018, 54, 5590-5593. [CrossRef] [PubMed]

99. Galiński, M.; Lewandowski, A.; Stępniak, I. Ionic liquids as electrolytes. Electrochim. Acta 2006, 51, 5567.

100. Sakaebe, H.; Matsumoto, H.; Tatsumi, K. Application of room temperature ionic liquids to Li batteries. Electrochim. Acta 2007, 53, 1048-1054. [CrossRef]

101. Mun, J.; Jung, Y.S.; Yim, T.; Lee, H.Y.; Kim, H.J.; Kim, Y.G.; Oh, S.M. Electrochemical stability of bis(trifluoromethanesulfonyl)imide-based ionic liquids at elevated temperature as a solvent for a titanium oxide bronze electrode. J. Power Sources 2009, 194, 1068-1074. [CrossRef]

102. Liu, K.; Zhou, Y.X.; Han, H.B.; Zhou, S.S.; Feng, W.F.; Nie, J.; Li, H.; Huang, X.J.; Armand, M.; Zhou, Z.B. Ionic liquids based on (fluorosulfonyl)(pentafluoroethanesulfonyl)imide with various oniums. Electrochim. Acta 2010, 55, 7145-7151. [CrossRef] 
103. Nguyen, D.Q.; Hwang, J.; Lee, J.S.; Kim, H.; Lee, H.; Cheong, M.; Lee, B.; Kim, H.S. Multi-functional zwitterionic compounds as additives for lithium battery electrolytes. Electrochem. Commun. 2007, 9, 109-114. [CrossRef]

104. Dong, T.; Zhang, L.; Chen, S.; Lu, X.; Zhang, S. A piperidinium-based ionic liquid electrolyte to enhance the electrochemical properties of $\mathrm{LiFePO}_{4}$ battery. Ionics 2015, 21, 2109-2117. [CrossRef]

105. Bucher, N.; Hartung, S.; Arkhipova, M.; Yu, D.; Kratzer, P.; Maas, G.; Srinivasan, M.; Hoster, H.E. A novel ionic liquid for $\mathrm{Li}$ ion batteries-uniting the advantages of guanidinium and piperidinium cations. RSC Adv. 2014, 4, 1996-2003. [CrossRef]

106. Elamin, K.; Shojaatalhosseini, M.; Danyliv, O.; Martinelli, A.; Swenson, J. Conduction mechanism in polymeric membranes based on PEO or PVdF-HFP and containing a piperidinium ionic liquid. Electrochim. Acta 2019, 299, 979-986. [CrossRef]

107. Vélez, J.F.; Vázquez-Santos, M.B.; Amarilla, J.M.; Herradón, B.; Mann, E.; del Río, C.; Morales, E. Geminal pyrrolidinium and piperidinium dicationic ionic liquid electrolytes. Synthesis, characterization and cell performance in $\mathrm{LiMn}_{2} \mathrm{O}_{4}$ rechargeable lithium cells. J. Power Sources 2019, 439, 227098. [CrossRef]

108. Liu, S.; Liedel, C.; Tarakina, N.V.; Osti, N.C.; Akcora, P. Dynamics of ionic liquids in the presence of polymer-grafted nanoparticles. Nanoscale 2019, 11, 19832-19841. [CrossRef]

109. Morales-Ugarte, J.E.; Benayad, A.; Santini, C.C.; Bouchet, R. Electrochemical Impedance Spectroscopy and X-ray Photoelectron Spectroscopy Study of Lithium Metal Surface Aging in Imidazolium-Based Ionic Liquid Electrolytes Performed at Open-Circuit Voltage. ACS Appl. Mater. Interfaces 2019, 11, 21955-21964. [CrossRef] [PubMed]

110. Vallet, P.; Parajó, J.J.; Sotuela, F.; López, M.V.; Cabeza, Ó.; Varela, L.M.; Salgado, J. Comparison of the Ionic Conductivity of Pure Imidazolium Nitrate and That Doped with a Lithium Nitrate Salt in Liquid and Gel Forms as Potential Electrolytes. Proceedings 2019, 41, 56. [CrossRef]

111. Ge, J.; Liang, H.; Zhou, M.; Zhao, C.; Zheng, Z.; Yan, Y.; Zhao, L.; Tang, K. Phosphonate-functionalized Ionic Liquid: A Novel Electrolyte Additive for Eenhanced Cyclic Stability and Rate Capability of $\mathrm{LiCoO}_{2}$ Cathode at High Voltage. Chem. Sel. 2019, 4, 9959-9965. [CrossRef]

112. Chen, N.; Guan, Y.; Shen, J.; Guo, C.; Qu, W.; Li, Y.; Wu, F.; Chen, R. Heteroatom Si Substituent Imidazolium-Based Ionic Liquid Electrolyte Boosts the Performance of Dendrite-Free Lithium Batteries. ACS Appl. Mater. Interfaces 2019, 11, 12154-12160. [CrossRef]

113. Bose, P.; Deb, D.; Bhattacharya, S. Lithium-polymer battery with ionic liquid tethered nanoparticles incorporated P(VDF-HFP) nanocomposite gel polymer electrolyte. Electrochim. Acta 2019, 319, 753-765. [CrossRef]

114. Zhang, S.; Lu, X.; Zhou, Q.; Li, X.; Zhang, X.; Li, S. Ionic Liquids: Physicochemical Properties; Elsevier Science: Amsterdam, The Netherlands, 2009.

115. Fernández-Miguez, L.; Vallet, P.; Tasende-Rodríguez, L.C.; Doval, A.; Villanueva, M.; Cabeza, Ó.; Varela, L.M.; Salgado, J.; Parajó, J.J. Thermophysical Characterization of TFSI Based Ionic Liquid and Lithium Salt Mixtures. Proceedings 2019, 41, 57. [CrossRef]

116. Eftekhari, A. Comment on "A Linear Actuation of Polymeric Nanofibrous Bundle for Artificial Muscles". Chem. Mater. 2010, 22, 2689-2690. [CrossRef]

117. Eftekhari, A. Comments on "Li diffusion in $\mathrm{LiNi}_{0.5} \mathrm{Mn}_{0.5} \mathrm{O}_{2}$ thin film electrodes prepared by pulsed laser deposition" by Xia et al. Electrochim. Acta 2010, 55, 3434. [CrossRef]

118. Eftekhari, A. Comment on "Carbon nanowalls as material for electrochemical transducers" [Appl. Phys. Lett. 95, 014104 (2009)]. Appl. Phys. Lett. 2010, 96, 126102. [CrossRef]

119. Endres, F.; Höfft, O.; Borisenko, N.; Gasparotto, L.H.; Prowald, A.; Al-Salman, R.; Carstens, T.; Atkin, R.; Bund, A.; Zein El Abedin, S. Do solvation layers of ionic liquids influence electrochemical reactions? Phys. Chem. Chem. Phys 2010, 12, 1724-1732. [CrossRef] [PubMed]

120. Hollóczki, O.; Malberg, F.; Welton, T.; Kirchner, B. On the origin of ionicity in ionic liquids. Ion pairing versus charge transfer. Phys. Chem. Chem. Phys 2014, 16, 16880-16890. [CrossRef]

121. Katsuta, S.; Imai, K.; Kudo, Y.; Takeda, Y.; Seki, H.; Nakakoshi, M. Ion Pair Formation of Alkylimidazolium Ionic Liquids in Dichloromethane. J. Chem. Eng. Data 2008, 53, 1528-1532. [CrossRef]

122. Kirchner, B.; Malberg, F.; Firaha, D.S.; Hollóczki, O. Ion pairing in ionic liquids. J. Phys. Condens. Matter 2015, 27, 463002. [CrossRef] 
123. Ma, K.; Forsman, J.; Woodward, C.E. Influence of ion pairing in ionic liquids on electrical double layer structures and surface force using classical density functional approach. J. Chem. Phys. 2015, 142, 174704. [CrossRef]

124. Zhao, W.; Leroy, F.; Heggen, B.; Zahn, S.; Kirchner, B.; Balasubramanian, S.; Müller-Plathe, F. Are There Stable Ion-Pairs in Room-Temperature Ionic Liquids? Molecular Dynamics Simulations of 1-n-Butyl-3-methylimidazolium Hexafluorophosphate. J. Am. Chem. Soc. 2009, 131, 15825-15833. [CrossRef]

125. Eftekhari, A.; Liu, Y.; Chen, P. Different roles of ionic liquids in lithium batteries. J. Power Sources 2016, 334, 221-239. [CrossRef]

126. Sun, L.; Morales-Collazo, O.; Xia, H.; Brennecke, J.F. Effect of Structure on Transport Properties (Viscosity, Ionic Conductivity, and Self-Diffusion Coefficient) of Aprotic Heterocyclic Anion (AHA) Room-Temperature Ionic Liquids. 1. Variation of Anionic Species. J. Phys. Chem. B 2015, 119, 15030-15039. [CrossRef] [PubMed]

127. Hayyan, M.; Mjalli, F.S.; Hashim, M.A.; AlNashef, I.M.; Mei, T.X. Investigating the electrochemical windows of ionic liquids. J. Ind. Eng. Chem. 2013, 19, 106-112. [CrossRef]

128. Eshetu, G.G.; Grugeon, S.; Laruelle, S.; Boyanov, S.; Lecocq, A.; Bertrand, J.-P.; Marlair, G. In-depth safety-focused analysis of solvents used in electrolytes for large scale lithium ion batteries. Phys. Chem. Chem. Phys 2013, 15, 9145-9155. [CrossRef] [PubMed]

129. Wasserscheid, P.; Welton, T. Outlook. In Ionic Liquids in Synthesis; Wiley-VCH: Weinheim, Germany, 2008; Volume 1, pp. 348-355.

130. Balducci, A. Ionic Liquids in Lithium-Ion Batteries. Top. Curr. Chem. 2017, 375, 20. [CrossRef] [PubMed]

131. Kirchner, B.; di Dio, P.J.; Hutter, J. Real-World Predictions from Ab Initio Molecular Dynamics Simulations. In Multiscale Molecular Methods in Applied Chemistry; Kirchner, B., Vrabec, J., Eds.; Springer: Berlin/Heidelberg, Germany, 2012; pp. 109-153.

132. Arnaiz, M.; Huang, P.; Ajuria, J.; Rojo, T.; Goikolea, E.; Balducci, A. Protic and Aprotic Ionic Liquids in Combination with Hard Carbon for Lithium-Ion and Sodium-Ion Batteries. Batter. Supercaps 2018, 1, $204-208$. [CrossRef]

133. Fleshman, A.M.; Mauro, N.A. Temperature-dependent structure and transport of ionic liquids with short-and intermediate-chain length pyrrolidinium cations. J. Mol. Liq. 2019, 279, 23-31. [CrossRef]

134. Domańska, U.; Królikowska, M.; Paduszyński, K. Physico-chemical properties and phase behaviour of piperidinium-based ionic liquids. Fluid Phase Equilib. 2011, 303, 1-9. [CrossRef]

135. Zhou, Y.; Wang, X.; Zhu, H.; Armand, M.; Forsyth, M.; Greene, G.W.; Pringle, J.M.; Howlett, P.C. N-ethyl-N-methylpyrrolidinium bis(fluorosulfonyl)imide-electrospun polyvinylidene fluoride composite electrolytes: Characterization and lithium cell studies. Phys. Chem. Chem. Phys 2017, 19, 2225-2234. [CrossRef]

136. Zhou, Y.; Wang, X.; Zhu, H.; Yoshizawa-Fujita, M.; Miyachi, Y.; Armand, M.; Forsyth, M.; Greene, G.W.; Pringle, J.M.; Howlett, P.C. Solid-State Lithium Conductors for Lithium Metal Batteries Based on Electrospun Nanofiber/Plastic Crystal Composites. Chem. Sus. Chem. 2017, 10, 3135-3145. [CrossRef]

137. Choi, J.; Manthiram, A. Role of Chemical and Structural Stabilities on the Electrochemical Properties of Layered $\mathrm{LiNi}_{1 / 3} \mathrm{Mn}_{1 / 3} \mathrm{Co}_{1 / 3} \mathrm{O}_{2}$ Cathodes. J. Electrochem. Soc. 2005, 152, A1714. [CrossRef]

138. Ohno, H.; Ito, K. Room-Temperature Molten Salt Polymers as a Matrix for Fast Ion Conduction. Chem. Lett. 1998, 27, 751-752. [CrossRef]

139. Shaplov, A.S.; Marcilla, R.; Mecerreyes, D. Recent Advances in Innovative Polymer Electrolytes based on Poly(ionic liquid)s. Electrochim. Acta 2015, 175, 18-34. [CrossRef]

140. Li, X.W.; Zhang, Z.X.; Li, S.J.; Yang, K.H.; Yang, L. Polymeric ionic liquid-ionic plastic crystal all-solid-state electrolytes for wide operating temperature range lithium metal batteries. J. Mater. Chem. A 2017, 5, 21362-21369. [CrossRef]

141. Yamaguchi, S.; Yamada,H.; Takeoka, Y.; Rikukawa, M.; Yoshizawa-Fujita, M. Synthesis of pyrrolidinium-based plastic crystals exhibiting high ionic conductivity at ambient temperature. New J. Chem. 2019, 43, 4008-4012. [CrossRef]

142. Yoshizawa-Fujita, M.; Kishi, E.; Suematsu, M.; Takekawa, T.; Rikukawa, M. A Plastic Electrolyte Material in a Highly Desirable Temperature Range: N-Ethyl-N-methylpyrrolidinium Bis(fluorosulfonyl)amide. Chem. Lett. 2014, 43, 1909-1911. [CrossRef] 
143. Janikowski, J.; Razali, M.R.; Forsyth, C.M.; Nairn, K.M.; Batten, S.R.; MacFarlane, D.R.; Pringle, J.M. Physical Properties and Structural Characterization of Ionic Liquids and Solid Electrolytes Utilizing the Carbamoylcyano(nitroso)methanide Anion. ChemPlusChem 2013, 78, 486-497. [CrossRef]

144. Hill, A.J.; Huang, J.; Efthimiadis, J.; Meakin, P.; Forsyth, M.; MacFarlane, D.R. Microstructural and molecular level characterisation of plastic crystal phases of pyrrolidinium trifluoromethanesulfonyl salts. Solid State Ionics 2002, 154-155, 119-124. [CrossRef]

145. MacFarlane, D.R.; Meakin, P.; Amini, N.; Forsyth, M. Structural studies of ambient temperature plastic crystal ion conductors. J. Phys. Condens. Matter 2001, 13, 8257-8267. [CrossRef]

146. Pas, S.J.; Huang, J.; Forsyth, M.; MacFarlane, D.R.; Hill, A.J. Defect-assisted conductivity in organic ionic plastic crystals. J. Chem. Phys. 2005, 122, 064704. [CrossRef]

147. Asha, S.; Vijayalakshmi, K.P.; George, B.K. Pyrrolidinium-based ionic liquids as electrolytes for lithium batteries: A Computational Study. Int. J. Quantum Chem. 2019, 119, 12. [CrossRef]

148. Pandian, S.; Hariharan, K.S.; Adiga, S.P.; Kolake, S.M. Evaluation of Electrochemical Stability and Li-ion Interactions in Ether Functionalized Pyrrolidinium and Phospholanium Ionic Liquids. J. Electrochem. Soc. 2020, 167, 070550. [CrossRef]

149. Eshetu, G.G.; Jeong, S.; Pandard, P.; Lecocq, A.; Marlair, G.; Passerini, S. Comprehensive Insights into the Thermal Stability, Biodegradability, and Combustion Chemistry of Pyrrolidinium-Based Ionic Liquids. ChemSusChem 2017, 10, 3146-3159. [CrossRef] [PubMed]

150. Francis, C.; Louey, R.; Sammut, K.; Best, A.S. Thermal Stability of Pyrrolidinium-FSI Ionic Liquid Electrolyte and Lithium-Ion Electrodes at Elevated Temperatures. J. Electrochem. Soc. 2018, 165, A1204-A1221. [CrossRef]

151. Francis, C.F.J.; Kyratzis, I.L.; Best, A.S. Lithium-Ion Battery Separators for Ionic-Liquid Electrolytes: A Review. Adv. Mater. 2020, 1904205. [CrossRef] [PubMed]

152. Eftekharnia, M.; Hasanpoor, M.; Forsyth, M.; Kerr, R.; Howlett, P.C. Toward Practical Li Metal Batteries: Importance of Separator Compatibility Using Ionic Liquid Electrolytes. ACS Appl. Energy Mater. 2019, 2, 6655-6663. [CrossRef]

153. Zheng, B.Z.; Zhu, J.P.; Wang, H.C.; Feng, M.; Umeshbabu, E.; Li, Y.X.; Wu, Q.H.; Yang, Y. Stabilizing Li10SnP2S12/Li Interface via an in Situ Formed Solid Electrolyte Interphase Layer. ACS Appl. Mater. Interfaces 2018, 10, 25473-25482. [CrossRef]

154. Heist, A.; Hafner, S.; Lee, S.H. High-Energy Nickel-Rich Layered Cathode Stabilized by Ionic Liquid Electrolyte. J. Electrochem. Soc. 2019, 166, A873-A879. [CrossRef]

155. Lewandowski, A.P.; Hollenkamp, A.F.; Donne, S.W.; Best, A.S. Cycling and rate performance of Li-LiFePO4 cells in mixed FSI-TFSI room temperature ionic liquids. J. Power Sources 2010, 195, 2029-2035. [CrossRef]

156. Moreno, M.; Simonetti, E.; Appetecchi, G.B.; Carewska, M.; Montanino, M.; Kim, G.T.; Loeffler, N.; Passerini, S. Ionic Liquid Electrolytes for Safer Lithium Batteries. J. Electrochem. Soc. 2016, 164, A6026-A6031. [CrossRef]

157. Huang, Q.W.; Lee, Y.Y.; Gurkan, B. Pyrrolidinium Ionic Liquid Electrolyte with Bis(trifluoromethylsulfonyl)imide and Bis(fluorosulfonyl)imide Anions: Lithium Solvation and Mobility, and Performance in Lithium Metal-Lithium Iron Phosphate Batteries. Ind. Eng. Chem. Res. 2019, 58, 22587-22597. [CrossRef]

158. Dahiya, P.P.; Patra, J.; Chang, J.K.; Sahoo, K.; Majumder, S.B.; Basu, S. Electrochemical characteristics of $0.3 \mathrm{Li}(2) \mathrm{MnO}(3)-0.7 \mathrm{LiMn}(1.5) \mathrm{Ni}(0.5) \mathrm{O}(4)$ composite cathode in pyrrolidinium-based ionic liquid electrolytes. J. Taiwan Inst. Chem. Eng. 2019, 95, 195-201. [CrossRef]

159. Wang, J.-Z.; Chou, S.-L.; Chew, S.-Y.; Sun, J.-Z.; Forsyth, M.; MacFarlane, D.R.; Liu, H.-K. Nickel sulfide cathode in combination with an ionic liquid-based electrolyte for rechargeable lithium batteries. Solid State Ionics 2008, 179, 2379-2382. [CrossRef]

160. Chou, S.-L.; Wang, J.-Z.; Sun, J.-Z.; Wexler, D.; Forsyth, M.; Liu, H.-K.; MacFarlane, D.R.; Dou, S.-X. High Capacity, Safety, and Enhanced Cyclability of Lithium Metal Battery Using a $\mathrm{V}_{2} \mathrm{O}_{5}$ Nanomaterial Cathode and Room Temperature Ionic Liquid Electrolyte. Chem. Mater. 2008, 20, 7044-7051. [CrossRef]

161. Sälzer, F.; Pateras Pescara, L.; Franke, F.; Müller, C.; Winkler, J.; Schwalm, M.; Roling, B. Assessing the Ion Transport Properties of Highly Concentrated Non-Flammable Electrolytes in a Commercial Li-Ion Battery Cell. Batter. Supercaps 2020, 3, 117-125. [CrossRef]

162. Seki, S.; Kobayashi, Y.; Miyashiro, H.; Ohno, Y.; Mita, Y.; Terada, N.; Charest, P.; Guerfi, A.; Zaghib, K. Compatibility of N-Methyl-N-propylpyrrolidinium Cation Room-Temperature Ionic Liquid Electrolytes and Graphite Electrodes. J. Phys. Chem. C 2008, 112, 16708-16713. [CrossRef] 
163. Park, J.H.; Moon, J.; Han, S.; Park, S.; Lim, J.W.; Yun, D.J.; Kim, D.Y.; Park, K.; Son, I.H. Formation of Stable Solid-Electrolyte Interphase Layer on Few-Layer Graphene-Coated Silicon Nanoparticles for High-Capacity Li-Ion Battery Anodes. J. Phys. Chem. C 2017, 121, 26155-26162. [CrossRef]

164. Domi, Y.; Usui, H.; Yamaguchi, K.; Yodoya, S.; Sakaguchi, H. Silicon-Based Anodes with Long Cycle Life for Lithium-Ion Batteries Achieved by Significant Suppression of Their Volume Expansion in Ionic-Liquid Electrolyte. ACS Appl. Mater. Interfaces 2019, 11, 2950-2960. [CrossRef]

165. Yodoya, S.; Domi, Y.; Usui, H.; Sakaguchi, H. Applicability of an Ionic Liquid Electrolyte to a Phosphorus-Doped Silicon Negative Electrode for Lithium-Ion Batteries. Chemistry Select 2019, 4, 1375-1378. [CrossRef]

166. Nguyen, C.C.; Song, S.-W. Characterization of SEI layer formed on high performance Si-Cu anode in ionic liquid battery electrolyte. Electrochem. Commun. 2010, 12, 1593-1595. [CrossRef]

167. Nair, J.R.; Colò, F.; Kazzazi, A.; Moreno, M.; Bresser, D.; Lin, R.; Bella, F.; Meligrana, G.; Fantini, S.; Simonetti, E.; et al. Room temperature ionic liquid (RTIL)-based electrolyte cocktails for safe, high working potential Li-based polymer batteries. J. Power Sources 2019, 412, 398-407. [CrossRef]

168. Singh, S.K.; Dutta, D.; Singh, R.K. Enhanced structural and cycling stability of Li2CuO2-coated $\mathrm{LiNi} 0.33 \mathrm{Mn} 0.33 \mathrm{Co} 0.33 \mathrm{O} 2$ cathode with flexible ionic liquid-based gel polymer electrolyte for lithium polymer batteries. Electrochim. Acta 2020, 343, 136122. [CrossRef]

169. Gupta, H.; Kataria, S.; Balo, L.; Singh, V.K.; Singh, S.K.; Tripathi, A.K.; Verma, Y.L.; Singh, R.K. Electrochemical study of Ionic Liquid based polymer electrolyte with graphene oxide coated LiFePO4 cathode for Li battery. Solid State Ion. 2018, 320, 186-192. [CrossRef]

170. Guerfi, A.; Dontigny, M.; Kobayashi, Y.; Vijh, A.; Zaghib, K. Investigations on some electrochemical aspects of lithium-ion ionic liquid/gel polymer battery systems. J. Solid State Electrochem. 2008, 13, 1003. [CrossRef]

171. Li, L.B.; Yang, X.Y.; Li, J.S.; Xu, Y.P. A novel and shortcut method to prepare ionic liquid gel polymer electrolyte membranes for lithium-ion battery. Ionics 2018, 24, 735-741. [CrossRef]

172. Yang, Y.; Wu, Q.; Wang, D.; Ma, C.; Chen, Z.; Zhu, C.; Gao, Y.; Li, C. Decoupling the mechanical strength and ionic conductivity of an ionogel polymer electrolyte for realizing thermally stable lithium-ion batteries. J. Membr. Sci. 2020, 595, 117549. [CrossRef]

173. Kim, D.; Liu, X.; Yu, B.; Mateti, S.; O’Dell, L.A.; Rong, Q.; Chen, Y. Amine-Functionalized Boron Nitride Nanosheets: A New Functional Additive for Robust, Flexible Ion Gel Electrolyte with High Lithium-Ion Transference Number. Adv. Funct. Mater. 2020, 30, 1910813. [CrossRef]

174. Wen, Z.; Li, Y.; Zhao, Z.; Qu, W.; Chen, N.; Xing, Y.; Ma, Y.; Li, L.; Wu, F.; Chen, R. A leaf-like Al2O3-based quasi-solid electrolyte with a fast $\mathrm{Li}+$ conductive interface for stable lithium metal anodes. J. Mater. Chem. A 2020, 8. [CrossRef]

175. Preibisch, Y.; Horsthemke, F.; Winter, M.; Nowak, S.; Best, A.S. Is the Cation Innocent? An Analytical Approach on the Cationic Decomposition Behavior of N-Butyl-N-methylpyrrolidinium Bis(trifluoromethanesulfonyl)imide in Contact with Lithium Metal. Chem. Mater. 2020, 32, 2389-2398. [CrossRef]

176. Pyschik, M.; Schultz, C.; Passerini, S.; Winter, M.; Nowak, S. Aging of Cations of Ionic Liquids Monitored by Ion Chromatography hyphenated to an Electrospray Ionization Mass Spectrometer. Electrochim. Acta 2015, 176, 1143-1152. [CrossRef]

177. Pyschik, M.; Winter, M.; Nowak, S. Determination and quantification of cations in ionic liquids by capillary electrophoresis-mass spectrometry. J. Chromatogr. A 2017, 1485, 131-141. [CrossRef]

178. Kroon, M.C.; Buijs, W.; Peters, C.J.; Witkamp, G.-J. Decomposition of ionic liquids in electrochemical processing. Green Chem. 2006, 8, 241-245. [CrossRef]

179. Grande, L.; von Zamory, J.; Koch, S.L.; Kalhoff, J.; Paillard, E.; Passerini, S. Homogeneous Lithium Electrodeposition with Pyrrolidinium-Based Ionic Liquid Electrolytes. ACS Appl. Mater. Interfaces 2015, 7, 5950-5958. [CrossRef] [PubMed]

180. Nürnberg, P.; Lozinskaya, E.I.; Shaplov, A.S.; Schönhoff, M. Li Coordination of a Novel Asymmetric Anion in Ionic Liquid-in-Li Salt Electrolytes. J. Phys. Chem. B 2020, 124, 861-870. [CrossRef] [PubMed]

181. Hoffknecht, J.P.; Drews, M.; He, X.; Paillard, E. Investigation of the N-butyl-N-methyl pyrrolidinium trifluoromethanesulfonyl-N-cyanoamide (PYR(14)TFSAM) ionic liquid as electrolyte for Li-ion battery. Electrochim. Acta 2017, 250, 25-34. [CrossRef] 
182. Pervez, S.A.; Kim, G.; Vinayan, B.P.; Cambaz, M.A.; Kuenzel, M.; Hekmatfar, M.; Fichtner, M.; Passerini, S. Overcoming the Interfacial Limitations Imposed by the Solid-Solid Interface in Solid-State Batteries Using Ionic Liquid-Based Interlayers. Small 2020, 16, 2000279. [CrossRef] [PubMed]

183. Cho, W.; Park, J.; Kim, K.; Yu, J.-S.; Jeong, G. Sulfide-Compatible Conductive and Adhesive Glue-Like Interphase Engineering for Sheet-Type All-Solid-State Battery. Small 2019, 6, 1902138. [CrossRef] [PubMed]

184. Li, J.; Downie, L.E.; Ma, L.; Qiu, W.; Dahn, J.R. Study of the Failure Mechanisms of LiNi0.8Mn0.1Co0.1O2 Cathode Material for Lithium Ion Batteries. J. Electrochem. Soc. 2015, 162, A1401-A1408. [CrossRef]

185. Balducci, A.; Jeong, S.S.; Kim, G.T.; Passerini, S.; Winter, M.; Schmuck, M.; Appetecchi, G.B.; Marcilla, R.; Mecerreyes, D.; Barsukov, V.; et al. Development of safe, green and high performance ionic liquids-based batteries (ILLIBATT project). J. Power Sources 2011, 196, 9719-9730. [CrossRef]

186. Di Lecce, D.; Hassoun, J. Lithium Metal Battery Using LiFe0.5Mn0.5PO4 Olivine Cathode and Pyrrolidinium-Based Ionic Liquid Electrolyte. ACS Omega 2018, 3, 8583-8588. [CrossRef]

187. McGrath, L.M.; Rohan, J.F. High-Rate Lithium-Ion Cycling in Electrodeposited Binder-Free Thin-Film Vanadium Oxide Cathodes with Lithium Metal Anodes in Ionic Liquid and Polymer Gel Analogue Electrolytes. Batter. Supercaps 2020. [CrossRef]

188. Sanchez-Ramirez, N.; Assresahegn, B.D.; Torresi, R.M.; Bélanger, D. Producing high-performing silicon anodes by tailoring ionic liquids as electrolytes. Energy Storage Mater. 2020, 25, 477-486. [CrossRef]

189. Piper, D.M.; Evans, T.; Leung, K.; Watkins, T.; Olson, J.; Kim, S.C.; Han, S.S.; Bhat, V.; Oh, K.H.; Buttry, D.A.; et al. Stable silicon-ionic liquid interface for next-generation lithium-ion batteries. Nat. Commun. 2015, 6, 6230. [CrossRef] [PubMed]

190. Kerner, M.; Johansson, P. Pyrrolidinium FSI and TFSI-Based Polymerized Ionic Liquids as Electrolytes for High-Temperature Lithium-Ion Batteries. Batteries 2018, 4, 10. [CrossRef]

191. Appetecchi, G.B.; Kim, G.T.; Montanino, M.; Carewska, M.; Marcilla, R.; Mecerreyes, D.; De Meatza, I. Ternary polymer electrolytes containing pyrrolidinium-based polymeric ionic liquids for lithium batteries. J. Power Sources 2010, 195, 3668-3675. [CrossRef]

192. Kimura, K.; Matsumoto, H.; Hassoun, J.; Panero, S.; Scrosati, B.; Tominaga, Y. A QuaternaryPoly(ethylene carbonate)-Lithium Bis(trifluoromethanesulfonyl)imide-Ionic Liquid-Silica Fiber Composite Polymer Electrolyte for Lithium Batteries. Electrochim. Acta 2015, 175, 134-140. [CrossRef]

193. Kim, J.-K.; Niedzicki, L.; Scheers, J.; Shin, C.-R.; Lim, D.-H.; Wieczorek, W.; Johansson, P.; Ahn, J.-H.; Matic, A.; Jacobsson, P. Characterization of N-butyl-N-methyl-pyrrolidinium bis(trifluoromethanesulfonyl)imide-based polymer electrolytes for high safety lithium batteries. J. Power Sources 2013, 224, 93-98. [CrossRef]

194. Choi, S.W.; Jo, S.M.; Lee, W.S.; Kim, Y.-R. An Electrospun Poly(vinylidene fluoride) Nanofibrous Membrane and Its Battery Applications. Adv. Mater. 2003, 15, 2027-2032. [CrossRef]

195. McGrath, L.M.; Jones, J.; Carey, E.; Rohan, J.F. Ionic Liquid Based Polymer Gel Electrolytes for Use with Germanium Thin Film Anodes in Lithium Ion Batteries. ChemistryOpen 2019, 8, 1429-1436. [CrossRef]

196. Kim, G.T.; Jeong, S.S.; Xue, M.Z.; Balducci, A.; Winter, M.; Passerini, S.; Alessandrini, F.; Appetecchi, G.B. Development of ionic liquid-based lithium battery prototypes. J. Power Sources 2012, 199, 239-246. [CrossRef]

197. Lahiri, A.; Borisenko, N.; Borodin, A.; Olschewski, M.; Endres, F. Characterisation of the solid electrolyte interface during lithiation/delithiation of germanium in an ionic liquid. Phys. Chem. Chem. Phys. 2016, 18, 5630-5637. [CrossRef]

198. Sano, M.; Tachikawa, N.; Yoshii, K.; Serizawa, N.; Katayama, Y. Electrodeposition of Tin in an Amide Type Ionic Liquid Containing Chloride Ion. Electrochemistry 2018, 86, 260-264. [CrossRef]

199. Wu, M.; Brooks, N.R.; Schaltin, S.; Binnemans, K.; Fransaer, J. Electrodeposition of germanium from the ionic liquid 1-butyl-1-methylpyrrolidinium dicyanamide. Phys. Chem. Chem. Phys 2013, 15, 4955-4964. [CrossRef] [PubMed]

200. Wu, M.; Vanhoutte, G.; Brooks, N.R.; Binnemans, K.; Fransaer, J. Electrodeposition of germanium at elevated temperatures and pressures from ionic liquids. Phys. Chem. Chem. Phys 2015, 17, 12080-12089. [CrossRef] [PubMed]

201. Lahiri, A.; Willert, A.; Abedin, S.Z.E.; Endres, F. A simple and fast technique to grow free-standing germanium nanotubes and core-shell structures from room temperature ionic liquids. Electrochim. Acta 2014, 121, 154-158. [CrossRef] 
202. Al-Salman, R.; Mallet, J.; Molinari, M.; Fricoteaux, P.; Martineau, F.; Troyon, M.; El Abedin, S.Z.; Endres, F. Template assisted electrodeposition of germanium and silicon nanowires in an ionic liquid. Phys. Chem. Chem. Phys 2008, 10, 6233-6237. [CrossRef]

203. Martineau, F.; Namur, K.; Mallet, J.; Delavoie, F.; Endres, F.; Troyon, M.; Molinari, M. Electrodeposition at room temperature of amorphous silicon and germanium nanowires in ionic liquid. IOP Conf. Ser. Mater. Sci. Eng. 2009, 6, 012012. [CrossRef]

204. Link, S.; Ivanov, S.; Dimitrova, A.; Krischok, S.; Bund, A. Understanding the initial stages of Si electrodeposition under diffusion kinetic limitation in ionic liquid-based electrolytes. J. Cryst. Growth 2020, 531, 125346. [CrossRef]

205. Choi, N.-S.; Lee, Y.; Kim, S.-S.; Shin, S.-C.; Kang, Y.-M. Improving the electrochemical properties of graphite/LiCoO2 cells in ionic liquid-containing electrolytes. J. Power Sources 2010, 195, 2368-2371. [CrossRef]

206. Lu, W.; Goering, A.; Qu, L.; Dai, L. Lithium-ion batteries based on vertically-aligned carbon nanotube electrodes and ionic liquid electrolytes. Phys. Chem. Chem. Phys 2012, 14, 12099-12104. [CrossRef]

207. Hofmann, A.; Schulz, M.; Hanemann, T. Effect of Conducting Salts in Ionic Liquid based Electrolytes: Viscosity, Conductivity, and Li-Ion Cell Studies. Int. J. Electrochem. Sci. 2013, 8, 10170-10189.

208. Mei, X.Y.; Yue, Z.; Tufts, J.; Dunya, H.; Mandal, B.K. Synthesis of new fluorine-containing room temperature ionic liquids and their physical and electrochemical properties. J. Fluorine Chem. 2018, 212, 26-37. [CrossRef]

209. Zhang, S.; Li, J.; Jiang, N.; Li, X.; Pasupath, S.; Fang, Y.; Liu, Q.; Dang, D. Rational Design of an Ionic Liquid-Based Electrolyte with High Ionic Conductivity Towards Safe Lithium/Lithium-Ion Batteries. Chem. Asian J. 2019, 14, 2810-2814. [CrossRef] [PubMed]

210. Fang, S.; Zhang, Z.; Jin, Y.; Yang, L.; Hirano, S.-i.; Tachibana, K.; Katayama, S. New functionalized ionic liquids based on pyrrolidinium and piperidinium cations with two ether groups as electrolytes for lithium battery. J. Power Sources 2011, 196, 5637-5644. [CrossRef]

211. Vogl, T.; Menne, S.; Kühnel, R.-S.; Balducci, A. The beneficial effect of protic ionic liquids on the lithium environment in electrolytes for battery applications. J. Mater. Chem. A 2014, 2, 8258-8265. [CrossRef]

212. Ferrari, S.; Quartarone, E.; Mustarelli, P.; Magistris, A.; Fagnoni, M.; Protti, S.; Gerbaldi, C.; Spinella, A. Lithium ion conducting PVdF-HFP composite gel electrolytes based on N-methoxyethyl-N-methylpyrrolidinium bis(trifluoromethanesulfonyl)-imide ionic liquid. J. Power Sources 2010, 195, 559-566. [CrossRef]

213. Sirisopanaporn, C.; Fernicola, A.; Scrosati, B. New, ionic liquid-based membranes for lithium battery application. J. Power Sources 2009, 186, 490-495. [CrossRef]

214. Fernicola, A.; Weise, F.C.; Greenbaum, S.G.; Kagimoto, J.; Scrosati, B.; Soleto, A. Lithium-Ion-Conducting Electrolytes: From an Ionic Liquid to the Polymer Membrane. J. Electrochem. Soc. 2009, 156, A514-A520. [CrossRef] [PubMed]

215. Fernicola, A.; Croce, F.; Scrosati, B.; Watanabe, T.; Ohno, H. LiTFSI-BEPyTFSI as an improved ionic liquid electrolyte for rechargeable lithium batteries. J. Power Sources 2007, 174, 342-348. [CrossRef]

216. Mei, X.Y.; Yue, Z.; Ma, Q.; Dunya, H.; Mandal, B.K. Synthesis and electrochemical properties of new dicationic ionic liquids. J. Mol. Liq. 2018, 272, 1001-1018. [CrossRef]

217. Al-Masri, D.; Yunis, R.; Zhu, H.J.; Jin, L.Y.; Bruce, P.; Hollenkamp, A.F.; Pringle, J.M. A new approach to very high lithium salt content quasi-solid state electrolytes for lithium metal batteries using plastic crystals. J. Mater. Chem. A 2019, 7, 25389-25398. [CrossRef]

Publisher's Note: MDPI stays neutral with regard to jurisdictional claims in published maps and institutional affiliations.

(C) 2020 by the authors. Licensee MDPI, Basel, Switzerland. This article is an open access article distributed under the terms and conditions of the Creative Commons Attribution (CC BY) license (http://creativecommons.org/licenses/by/4.0/). 